\title{
Insights into the Simultaneous Sorption of Ciprofloxacin and Heavy Metals Using Functionalized Biochar
}

\author{
Agnieszka Cuprys ${ }^{1,2, * \mathbb{C}}$, Zakhar Maletskyi ${ }^{2} \mathbb{D}$, Tarek Rouissi ${ }^{1,3}$, Harsha Ratnaweera ${ }^{2}$, Satinder Kaur Brar ${ }^{1,4, *}$, \\ Emile Knystautas ${ }^{5}$ and Patrick Drogui ${ }^{1}$ \\ 1 INRS-ETE, Université du Québec, 490, Rue de la Couronne, QC G1K 9A9, Canada; \\ tarek.rouissi@ete.inrs.ca (T.R.); patrick.drogui@inrs.ca (P.D.) \\ 2 Faculty of Science and Technology (REALTEK), Norwegian University of Life Sciences, P.O. Box 5003, \\ 1432 Ås, Norway; zakhar.maletskyi@nmbu.no (Z.M.); harsha.ratnaweera@nmbu.no (H.R.) \\ 3 School of the Environment, Laurentian University, 935 Ramsey Lake Rd, Sudbury, ON P3E 2C6, Canada \\ 4 Department of Civil Engineering, Lassonde School of Engineering, York University, North York, \\ Toronto, ON M3J 1P3, Canada \\ 5 Department of Physics, of Physical and Optical Engineering, Faculty of Science and Engineering, \\ Laval University, Pavillon Alexandre-Vachon, 1045, av. de la Médecine, Québec, QC G1V 0A6, Canada; \\ Emile.Knystautas@phy.ulaval.ca \\ * Correspondence: agnieszka.cuprys@nmbu.no (A.C.); Satinder.Brar@lassonde.yorku.ca (S.K.B.); \\ Tel.: +47-672-3148 (A.C.); +1-(416)-736-2100 (ext. 55228) (S.K.B.)
}

check for updates

Citation: Cuprys, A.; Maletskyi, Z.; Rouissi, T.; Ratnaweera, H.; Brar, S.K.; Knystautas, E.; Drogui, P. Insights into the Simultaneous Sorption of Ciprofloxacin and Heavy Metals Using Functionalized Biochar. Water 2021, 13, 2768. https://doi.org/ 10.3390/w13192768

Academic Editor: Miren López de Alda Villaizán

Received: 24 August 2021

Accepted: 28 September 2021

Published: 6 October 2021

Publisher's Note: MDPI stays neutral with regard to jurisdictional claims in published maps and institutional affiliations.

Copyright: (c) 2021 by the authors. Licensee MDPI, Basel, Switzerland. This article is an open access article distributed under the terms and conditions of the Creative Commons Attribution (CC BY) license (https:/ / creativecommons.org/licenses/by/ $4.0 /)$.

\begin{abstract}
Biochar and chitosan are considered as green and cost-effective adsorbents for water purification; the combination of these two materials may lead to an improved adsorption capacity of the generated adsorbents. Most sorption studies have been focused on the ability to adsorb one contaminant or the same type of contaminants. Thus, this study aimed to produce chitosan-biochar beads (CH-BB) and test their efficiency in the simultaneous removal of a metal-complexing antibiotic, ciprofloxacin (CIP), and three metal(loid)s (As, $\mathrm{Cd}$ and $\mathrm{Pb}$ ). Modification of raw pig manure biochar resulted in an increase in its adsorption capacity, except for $\mathrm{Pb}$. The highest increment was observed for As (almost 6-fold) and the lowest was observed for CIP (1.1-fold). The adsorbent was able to simultaneously remove all targeted contaminants, individually and in the mixture. The adsorption capacity of $\mathrm{CH}-\mathrm{BB}$ followed the order: $\mathrm{Pb}>\mathrm{Cd}>>\mathrm{As}>\mathrm{CIP}$. When $\mathrm{Pb}$ and As were present in the same mixture, their removal efficiency increased from $0.13 \pm 0.01$ to $0.26 \pm 0.05 \mathrm{mg} / \mathrm{g}$ for As and from $0.75 \pm 0.08$ to $0.85 \pm 0.02 \mathrm{mg} / \mathrm{g}$ for $\mathrm{Pb}$ due to their co-precipitation. The CIP-metal complexation probably resulted in a reduced adsorption ability for inorganics due to the decreased concentration of free ions. The presence of metals and metalloids led to alterations in CIP's mobility.
\end{abstract}

Keywords: ciprofloxacin; heavy metals; adsorption; biochar; chitosan; wastewater

\section{Introduction}

Water pollution is a growing global concern. Contamination with potentially harmful elements, especially heavy metals, is considered a severe environmental threat [1]. All of these occur in the environment naturally at lower concentrations (parts per million) [2]. However, due to anthropogenic activities, their concentration has increased significantly [1].

Arsenic (As), lead $(\mathrm{Pb})$ and cadmium $(\mathrm{Cd})$ are considered among the first ten chemicals with a significant public health concern, listed by the World Health Organization (WHO) [3]. As (metalloid) and Cd (heavy metal) are known cancerogenic agents; $\mathrm{Pb}$ (heavy metal) has a cumulative toxic effect on many body systems. All three occur naturally in the Earth's crust, minerals, e.g., arsenopyrite (As), sphalerite (Cd), chalcopyrite $(\mathrm{Cd})$ and galena $(\mathrm{Pb})$, and sedimentary or igneous rocks [4-6]. The metal(loid)s or their water-soluble salts might slowly leach to groundwater, which can further be transported to surface water. The main anthropogenic sources of these metal(loid)s include extensive mining, smelting, 
inappropriate waste management or burning of fossil fuels [4-6]. The usage of metal(loid)containing products such as petrol $(\mathrm{Pb})$, paint $(\mathrm{Pb})$, fertilizers $(\mathrm{Cd})$ or wood and leather preservatives (As) also contributes to their presence in the environment [4-6].

On the other hand, there are many various groups of different substances that are non-monitored and enter aquatic compartments at low concentrations (ng- $\mu \mathrm{g} / \mathrm{L}$ ). This group of emerging contaminants includes personal care products, flame retardants, plastics and pharmaceuticals. Their presence in the environment can pose adverse problems; for example, bisphenol A, a common plasticizer, is well known for its toxic effect on aquatic organisms and its endocrine disruption potency [7]. Another alarming presence in the environment is the presence of antibiotics with well-documented evidence of environmental risks, particularly antimicrobial resistance and risks for human health [8]. For instance, fluoroquinolones, broad-spectrum antibiotics, have been classified by the WHO as critically important antibacterial agents for human medicine due to their increased propensity to develop resistance [9]. The representative of this group, ciprofloxacin (CIP), is one of the most frequently prescribed fluoroquinolones worldwide [10]. Once it enters the human body, up to $65 \%$ of CIP is not metabolized and excreted in the urine and/or feces; therefore, it can enter the environment through wastewater [11]. The presence of CIP in water and soils has led to increased antimicrobial resistance throughout the years [10]. Additionally, it is persistent and not easily biodegradable.

Furthermore, the co-existence of heavy metals and antibiotics in the environment is highly alarming. First of all, antibiotics such as CIP may form complexes with heavy metals. CIP-metal complexation may result in alterations in mobility and solubility, and, sometimes, in increased antimicrobial properties of antibiotics [11]. Such complexes can be more persistent in the environment than antibiotics alone [11]. Hence, one can assume that CIP-metal complexes may be more difficult to remove. Additionally, this may lead to the promotion of antimicrobial resistance. The positive correlation between the presence of heavy metals and some antimicrobial-resistant genes has been reported previously $[8,12]$. Studies have shown that genes for resistance to antibiotics and heavy metals may be present in the same bacterial plasmid. Thus, the presence of heavy metals and/or certain antibiotics may exert selective pressure on the bacteria and disseminate both types of resistance simultaneously [8,12]. Based on the review by Nguyen et al. (2019), Cd was one of the metals most commonly associated with antimicrobial resistance, where $\mathrm{Pb}$ and $\mathrm{As}$ contributed to its dissemination at a lower scale [13].

To address the problem of water pollution, scientists have been conducting extensive studies of novel water treatment methods. However, their research has mostly been focused on the removal of one compound [14-16] or the same type of compounds [17-19], while it is essential to remove pollutants simultaneously from the environment. To tackle the problem of metal and antibiotic co-contamination, adsorption has been proven as a promising solution due to its simplicity and cost effectiveness. The most affordable candidates as adsorbents are materials obtained from agricultural or food industry waste. Biochar is a carbon-rich material acquired from biomass pyrolysis that has gained interest due to its microporous structure, high surface area and more economical and less energy-consuming production, as compared to commercially available activated carbon [20]. However, raw biochar may exhibit a relatively lower adsorption capacity towards many organic and inorganic pollutants, especially anions, due to repulsion between negatively charged surfaces [21]. This can be resolved by the addition of chitosan. It is a natural polymer, obtained via deacetylation of chitin from crustacean waste. Chitosan has been previously tested in agriculture, as a plant growth promoter, or in biomedicine due to its antimicrobial and antioxidant properties [22]. Moreover, it can be used as a water purification agent due to its chelating potency [22]. Its amine groups can enhance the adsorption capacity of the modified material [23]. Chitosan is also considered as cost-effective, biodegradable and non-toxic [22,23].

The combination of these two biomaterials, i.e., biochar and chitosan, has efficiently removed metal ions $[19,21]$ and organic pollutants $[21,24]$. However, to the best of the 
authors' knowledge, there has not been a study that has investigated the simultaneous removal of metal(loid)s and antibiotics via chitosan-modified biochar. Hence, the key aim of this study was to use chitosan-biochar hydrogel beads to investigate the simultaneous removal of antibiotics' representative, CIP, two heavy metals, i.e., lead and cadmium, and one metalloid, arsenic. The influence of various contact times and contaminant concentrations was evaluated. Adsorption studies were performed for targeted pollutants individually and in the mixture. Additionally, the removal efficiency was also measured in real wastewater.

\section{Materials and Methods}

\subsection{Materials}

CIP (98\% purity) was purchased from Acros Organics (Morris Plains, NJ, USA). HPLC-grade methanol (purity $>99.8 \%$ ) and HPLC-grade acetic acid (purity $>99.7 \%$ ) were obtained from Fisher Scientific (Ottawa, ON, Canada). Low-molecular weight chitosan (50-160 kDa, 75-85\% deacetylated) and sodium arsenate dibasic heptahydrate (purity $>98 \%$ ) were obtained from Sigma Aldrich (Oakville, ON, Canada). Sodium hydroxide (pellet) and disodium ethylenediaminetetraacetate $\left(\mathrm{Na}_{2} \mathrm{H}_{2} \mathrm{EDTA}, 99 \%\right)$ were purchased from Merck (Darmstadt, Germany). Cadmium sulfate (purity 98\%) and lead sulfate (purity $>99.9 \%$ ) were obtained from VWR (ON, Canada). Standards and internal standards for metal detection were purchased from Inorganic Ventures (Christiansburg, VA, USA). Nitric acid (65\%) was obtained from Normapur and 37\% hydrochloric acid from EMSURE. Deionized 18.2 $\mathrm{M} \Omega$ type I water was used for both standards and samples.

The lead stock solution was prepared by dissolving lead sulfate in a mixture of 1:1 nitric and hydrochloric acid, and its final concentration was determined by ICP-MS. Cadmium stock solution was prepared by dissolving cadmium sulfate in deionized water with nitric acid. The arsenic stock solution was prepared by dissolving sodium arsenate in deionized water.

Pinewood biochar (PW-BC) and almond shell biochar (AS-BC) were acquired from Pyrovac Inc. (Quebec, QC, Canada). Pig manure (PM-BC) was donated by the Research and Development Institute for Agri-Environment (IRDA), Quebec, Canada. The details of their production are presented in Table S1. The FTIR spectra of raw biochars are shown in Figure S1. The characterization of each biochar was described previously $[25,26]$. All biochars were grounded to make a fine powder and sieved through a uniform sieve size of $0.25 \mathrm{~mm}$. The prepared biochar samples were preserved at room temperature for further analyses.

\subsection{Chitosan-Biochar Beads}

The initial adsorption capacity of three biochars was tested in batch sorption experiments to choose the most suitable material. All experiments were conducted at room temperature $\left(20 \pm 2{ }^{\circ} \mathrm{C}\right), \mathrm{pH}$ 6.0, $150 \mathrm{rpm}$ in an orbital shaker (PSU-20i Multi-functional Orbital Shaker, Biosan). About $0.05 \mathrm{~g}$ of biochar was added to a $100 \mathrm{~mL}$ container and mixed with a $50 \mathrm{~mL}$ solution of each contaminant $(10 \mathrm{mg} / \mathrm{L}$ for CIP/As/Cd and $1 \mathrm{mg} / \mathrm{L}$ for $\mathrm{Pb}$ ). A lower concentration of $\mathrm{Pb}$ ions was maintained, avoiding the precipitation of the salt due to circumneutral $\mathrm{pH}$. The results are discussed in the Supplementary Data. The biochar with the highest adsorption capacity, i.e., $\mathrm{PM-BC}$, was then used to generate chitosan-biochar beads (CH-BB).

$\mathrm{CH}-\mathrm{HB}$ were prepared as described by Azfal et al. (2018) with minor modifications [24]. Briefly, $1.67 \mathrm{mg} / \mathrm{L}$ of chitosan was dissolved overnight in $2 \%$ acetic acid at room temperature $\left(20 \pm 2{ }^{\circ} \mathrm{C}\right)$. Biochar was added (1:1 biochar/chitosan), and the mixture was stirred for $2 \mathrm{~h}$. The prepared suspension was then added dropwise to $0.6 \mathrm{M} \mathrm{NaOH}$ and left overnight at room temperature $\left(20 \pm 2{ }^{\circ} \mathrm{C}\right)$. Generated beads were then separated and repeatedly washed to remove the excess $\mathrm{NaOH}$. Subsequently, the beads were dried $\left(60^{\circ} \mathrm{C}\right)$ and kept at room temperature $\left(20 \pm 2{ }^{\circ} \mathrm{C}\right)$ for further use. 


\section{3. $\mathrm{CH}$-BH Characterization}

The morphology of $\mathrm{CH}-\mathrm{BH}$ was obtained via scanning electron microscopy (SEM) $\left(\right.$ CarlZeissEVO $\left.{ }^{\circledR} 50\right)$. SEM micrographs were taken at $10 \mathrm{kV}$ accelerating voltage. The samples were not gold coated. The zeta potential was determined by the Malvern Zetasizer Nano-ZS particle analyzer. The surface area was investigated using $\mathrm{N}_{2}$ adsorption isotherms and the Brauner-Emmett-Teller (BET) method to evaluate the mesoporeenclosed surface area. Fourier transform infrared spectroscopy (FT-IR) spectra of adsorbents before and after adsorption were obtained via a Nicolet FT-IR system (Thermofisher Scientific, Boston, MA, USA). The spectra were taken at a resolution of $4 \mathrm{~cm}^{-1}$ at the scale of $4000-400 \mathrm{~cm}^{-1}$.

A metal leaching test from $\mathrm{CH}-\mathrm{BB}$ was performed: around $0.1 \mathrm{~g}$ of beads was added to $100 \mathrm{~mL}$ of deionized water, and the solution was left at room temperature for $48 \mathrm{~h}$. Element concentrations were then analyzed via inductively coupled plasma mass spectrometry (ICP-MS) (Agilent Technologies 8800 ICP-MS Triple Quad).

\subsection{Adsorption Experiments}

The individual influence of $\mathrm{pH}$ on the adsorption ability of CIP, the heavy metals and the metalloid was tested. The obtained results are discussed in the Supplementary Data. Based on these experiments, $\mathrm{pH} 6.0$ was chosen for all adsorption tests. Additionally, the selected $\mathrm{pH}$ falls in the range of the $\mathrm{pH}$ of real wastewater. Thus, all experiments, described below, were conducted at room temperature $\left(20 \pm 2{ }^{\circ} \mathrm{C}\right), \mathrm{pH} 6.0,150 \mathrm{rpm}$, in an orbital shaker (PSU-20i Multi-functional Orbital Shaker, Biosan), unless stated otherwise. Blank experiments were included.

Metal concentrations were estimated via ICP-MS (Agilent Technologies 8800 ICP-MS Triple Quad) (Section 2.5). CIP concentration was measured via UV-Vis spectrophotometry (UV-T500Pro) at a wavelength of $278 \mathrm{~nm}$, unless stated otherwise. CIP absorbance is affected by the metal ions in the matrix [27]. The metals present in biochar and beads may leach into the solution (Table S2). Hence, to avoid false negative and/or false positive results, all samples with $\mathrm{CIP}$ were diluted with $0.1 \mathrm{M} \mathrm{HCl}(1: 1)$ to protonate $\mathrm{CIP}\left(\mathrm{CIP}^{+}\right)$and release it from metal complexation.

The amount of CIP and metals " $q_{e}$ " (mg/g) retained in the solid phase, at equilibrium, was estimated by a mass balance between the initial and final states (Equation (1)):

$$
q_{e}=\frac{\left(C_{0}-C_{e}\right) V}{m}
$$

where $C_{0}$ and $C_{e}$ are the initial and equilibrium concentrations, respectively, $V(\mathrm{~L})$ is the solution volume, and $m(\mathrm{~g})$ stands for the weight of the adsorbent.

Adsorption potency: The individual adsorption experiments were performed by adding the contaminants to $50 \mathrm{~mL}$ ultrapure water $(\mathrm{pH}$ 6.0). The $\mathrm{pH}$ was measured after pollutant additions and readjusted where needed. The final concentration was set at $10 \mathrm{mg} / \mathrm{L}$ for $\mathrm{CIP}$, As and $\mathrm{Cd}$, and $1 \mathrm{mg} / \mathrm{L}$ for $\mathrm{Pb}$. Subsequently, $50 \mathrm{mg}$ of $\mathrm{CH}-\mathrm{BB}$ was added, and the prepared solution was shaken for $48 \mathrm{~h}$.

Adsorption isotherms and kinetics: To obtain sorption isotherms, $\mathrm{CH}-\mathrm{HB}$ was shaken with contaminants individually in a range of $2-100 \mathrm{mg} / \mathrm{L}$ (CIP, Cd), $0.25-50 \mathrm{mg} / \mathrm{L}$ (As) or $0.5-2 \mathrm{mg} / \mathrm{L}(\mathrm{Pb})$. All samples were filtered via $0.22 \mu \mathrm{m}$ PFTE syringe filters (VWR), and the filtrate was further diluted accordingly before measurement. For kinetic studies, adsorption experiments were performed individually $(1 \mathrm{mg} / \mathrm{L}$ of metal or CIP) and in a mixture ( $1 \mathrm{mg} / \mathrm{L}$ each of metals and CIP).

Co-adsorption studies: The co-adsorption experiments were performed by adding mixture contaminants to $50 \mathrm{~mL}$ ultrapure water $(\mathrm{pH} 6.0)$. The $\mathrm{pH}$ was measured after pollutant additions and readjusted where needed. The metal concentration remained constant $(4 \mathrm{mg} / \mathrm{L})$, while the CIP concentration ranged between 0.5 and $20 \mathrm{mg} / \mathrm{L}$. Subsequently, $50 \mathrm{mg}$ of $\mathrm{CH}-\mathrm{BB}$ was added, and the prepared solution was shaken for $48 \mathrm{~h}$. 
Tests in real wastewater: The treated wastewater was taken from a pilot-scale wastewater treatment plant at the Norwegian University of Life Sciences, Ås, Norway. Samples were spiked with $1 \mathrm{mg} / \mathrm{L}$ of $\mathrm{As}, \mathrm{Cd}, \mathrm{Pb}$ and $\mathrm{CIP}$, and the $\mathrm{pH}$ was adjusted to 6.0. Adsorption experiments were performed by adding $50 \mathrm{mg}$ of $\mathrm{CH}-\mathrm{BB}$ to $50 \mathrm{~mL}$ of prepared wastewater and shaking for $24 \mathrm{~h}, 150 \mathrm{rpm}$, at $20 \pm 1{ }^{\circ} \mathrm{C}$. To evaluate the removal efficiency of the generated adsorbent, comparison tests between $\mathrm{CH}-\mathrm{BB}, \mathrm{PM}-\mathrm{BC}$ and commercial granulated active carbon (GAC, Filtrasorb 400) were performed. PM-BC and GAC were sieved to obtain the same particle size as $\mathrm{CH}-\mathrm{BB}$. After adsorption experiments, the samples were filtered through $0.22 \mu \mathrm{m}$ PFTE syringe filters. The filtrates were then analyzed for heavy metal and metalloid concentrations via ICP-MS-MS. The residual concentration of CIP was detected via liquid chromatography coupled with tandem mass spectrometry (LC-MS/MS), as described previously [15]. Table 1 briefly summarizes the analytical method.

Table 1. The summary of analysis of CIP via LC-MS/MS.

\begin{tabular}{|c|c|}
\hline Liquid chromatography instrument & $\begin{array}{c}\text { Finnigan surveyor LC pump (Thermo Scientific, } \\
\text { Mississauga, ON, Canada) }\end{array}$ \\
\hline Detection & $\begin{array}{l}\text { TSQ Quantum access triple quadruple mass spectrometer } \\
\text { (Thermo Scientific, Mississauga, ON, Canada) }\end{array}$ \\
\hline Ionization & Electrospray \\
\hline Column & $\begin{array}{c}\text { BetaBasic-18 }(100 \mathrm{~mm} \times 2.1 \mathrm{~mm} \times 3 \mu \mathrm{m})(\text { Thermo } \\
\text { Scientific, Mississauga, ON, Canada })\end{array}$ \\
\hline Oven temperature & $40^{\circ} \mathrm{C}$ \\
\hline Flow rate & $0.3 \mathrm{~mL} / \mathrm{min}$ \\
\hline SRM mode & Positive \\
\hline Spray voltage & $4000 \mathrm{~V}$ \\
\hline Skimmer off-set & $20 \mathrm{~V}$ \\
\hline Gas pressure & 1.5 mTorr \\
\hline Capillary temperature & $350^{\circ} \mathrm{C}$ \\
\hline Injection volume & $10 \mu \mathrm{L}$ \\
\hline Internal standard & Ciprofloxacin- $\mathrm{d}_{8}\left(\mathrm{CIP}-\mathrm{d}_{8}\right)$ \\
\hline Mobile phase & $\begin{array}{c}\text { A: } 0.1 \% \text { formic acid } \\
\text { B: acetonitrile }+0.1 \% \text { formic acid }\end{array}$ \\
\hline Collision energy & $\begin{array}{c}\text { CIP: } 17 \mathrm{~V} \\
\text { CIP-d }: 19 \mathrm{~V}\end{array}$ \\
\hline Precursor ions & $\begin{array}{c}\text { CIP: } 332.3 \mathrm{~m} / \mathrm{z} \\
\text { CIP-d }: 340.3 \mathrm{~m} / \mathrm{z}\end{array}$ \\
\hline Product ions & $\begin{array}{c}\text { CIP: } 245.3 \mathrm{~m} / \mathrm{z} \\
\text { CIP- } \mathrm{d}_{8}: 249.3 \mathrm{~m} / \mathrm{z}\end{array}$ \\
\hline
\end{tabular}

\subsection{ICP}

All analyses were performed using an Agilent Technologies 8800 Triple Quad ICPQQQ with a collision/reaction cell (CRC). The instrumental method for simultaneous measurement of $\mathrm{As}, \mathrm{Cd}$ and $\mathrm{Pb}$ with oxygen as the reaction gas was provided by Karl Andreas Jensen from the Norwegian University of Life Sciences, Faculty of Environmental Sciences and Natural Resource Management. Robust instrument settings, together with the oxygen reaction gas, were chosen due to the high concentrations used in the experiments. A quality control standard was performed every 10-12 samples for instrument drift. 
Mass 118 was monitored for mathematical removal of any isobar contribution from natural isotopes of both ${ }^{114} \mathrm{Cd}$ and internal standard ${ }^{115} \mathrm{In}$. Mo $95->127$ was also monitored to verify low interference levels on ${ }^{114} \mathrm{Cd}$ determination from ${ }^{98} \mathrm{Mo}^{16} \mathrm{O}^{+}$and ${ }^{96} \mathrm{Mo}^{18} \mathrm{O}^{+}$. The lead was determined as the sum of the three major isotopes, as variations from isotopic ratios change depending on the source of lead, using Equations (2)-(4).

$$
\begin{gathered}
{ }^{208} \mathrm{~Pb}=\mathrm{M}(206->206)+\mathrm{M}(207->207)+\mathrm{M}(208->208) \\
{ }^{114} \mathrm{Cd}=\mathrm{M}(114->114)-\mathrm{M}(118->118) \times 0.0268 \\
{ }^{115} \mathrm{In}=\mathrm{M}(115->115)-\mathrm{M}(118->118) \times 0.0140
\end{gathered}
$$

\subsection{Statistical Analysis}

The results are displayed as means of triplicates \pm standard deviations. One-way analysis of variance (ANOVA) was used to assess statistically significant differences ( $p$-values $<0.05)$ and was executed using SigmaPlot 13.0.

The parameters of the kinetic and isotherm models were calculated using Microsoft Excel's Solver add-in via trial-and-error nonlinear methods. Moreover, apart from the coefficient of determination $\left(R^{2}\right)$ of the nonlinear optimization (Equation (5)), the root mean square error $(E)$ (Equation (6)) and chi-squared $\left(\chi^{2}\right)$ (Equation (7)) value were determined for each model.

$$
\begin{aligned}
R^{2} & =1-\frac{\sum\left(q_{e, \exp }-q_{e, m}\right)^{2}}{\sum\left(q_{e, \exp }-q_{e, \text { mean }}\right)^{2}} \\
E & =\sqrt{\frac{1}{n} \sum^{n}\left(q_{e, m}-q_{e, \exp }\right)^{2}} \\
\chi & =\sum \frac{\left(q_{e, \exp }-q_{e, m}\right)^{2}}{q_{e, m}}
\end{aligned}
$$

where $q_{e, \text { exp }}(\mathrm{mg} / \mathrm{g})$ is the amount of pollutants adsorbed at equilibrium obtained from Equation (1), $q_{e, m}(\mathrm{mg} / \mathrm{g})$ is the calculated adsorption capacity at equilibrium after using the Solver add-in, and $q_{e, \text { mean }}(\mathrm{mg} / \mathrm{g})$ is the mean value of $q_{e, \text { exp. }}$.

\section{Results}

\subsection{Chitosan-Biochar Beads}

\subsubsection{Fabrication}

To generate $\mathrm{CH}-\mathrm{BB}$, suitable raw biochar had to be chosen. The comparison of the adsorption capacity between PW-BC, AS-BC and PM-BC was carried out, which is presented in Table S3. Based on the results, discussed in the Supplementary Data, PM-BC was selected for the fabrication of $\mathrm{CH}-\mathrm{BB}$.

\subsubsection{Characterization}

FT-IR: To detect functional groups present in the generated adsorbent, as well as the binding sites of targeted pollutants, FT-IR analysis was carried out. The results are presented in Figure 1. The surface of $\mathrm{CH}-\mathrm{BB}$ differs from raw PM-BC. The wide peak between 3000 and $3600 \mathrm{~cm}^{-1}$ in PM-BC belongs to O-H stretching. In $\mathrm{CH}-\mathrm{BB}$, this region changed, and the peak shifted and widened, suggesting the additional presence of an amino group [24]. The peak at $2960 \mathrm{~cm}^{-1}$ corresponds to the presence of aliphatic hydrocarbons and stretching vibrations of $-\mathrm{CH} /-\mathrm{CH}_{2}$ groups. The band at $1660 \mathrm{~cm}^{-1}$ belongs to $\mathrm{C}=\mathrm{O}$ vibrations. Three peaks at 1190 (C-O-C stretching), 1100 and $1030 \mathrm{~cm}^{-1}$ (C-O stretching) can be identified as characteristic bands for the saccharide chitosan structure [24]. 


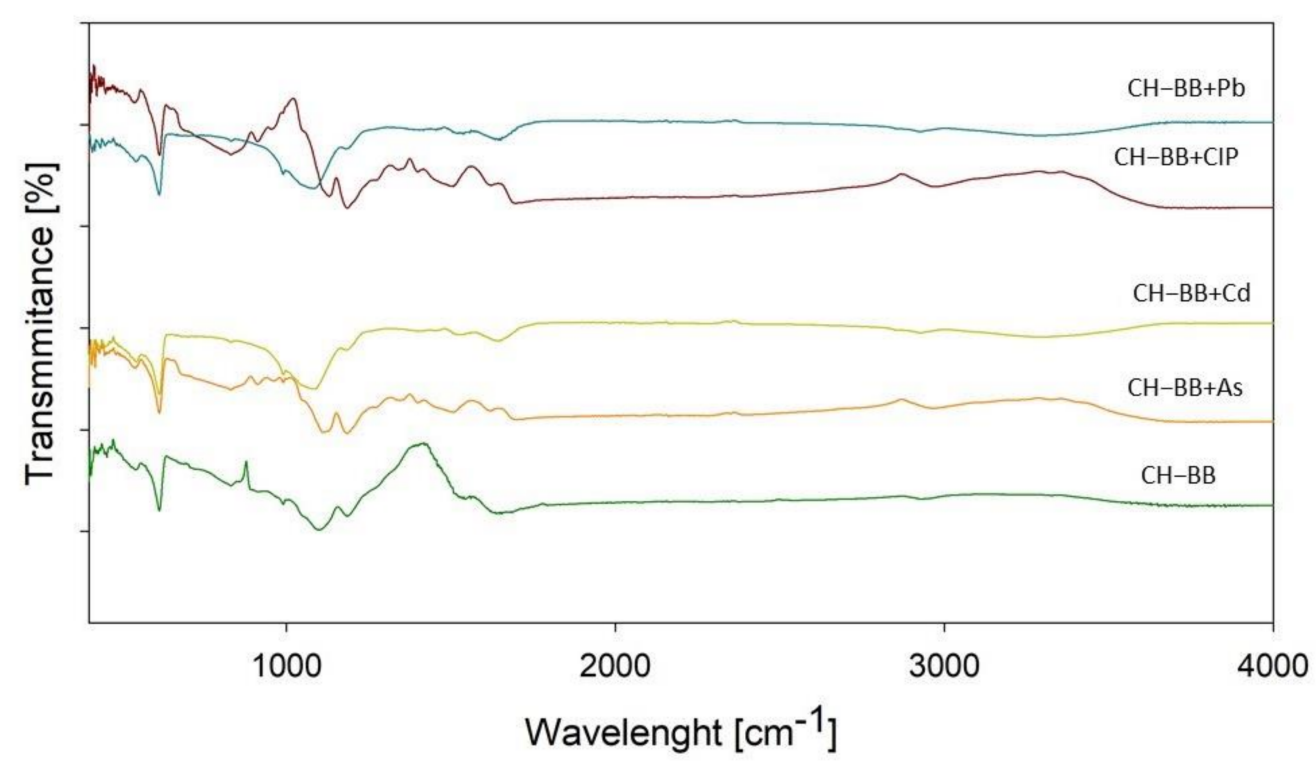

Figure 1. FTIR of $\mathrm{CH}-\mathrm{BB}$ before and after adsorption of CIP or heavy metals. $\mathrm{CH}-\mathrm{BB}$ - chitosanbiochar beads; CIP—ciprofloxacin.

The presence of contaminants altered the FT-IR spectra of CH-BB (Figure 1), which allowed the identification of potential binding sites. The adsorption of $\mathrm{Cd}$ and $\mathrm{Pb}$ was via the hydroxyl group, as evidenced by the disappearance of the peak in the region between 3000 and $3500 \mathrm{~cm}^{-1}$. In the case of As and CIP, a sharp, wide shoulder appeared at $3400 \mathrm{~cm}^{-1}$. This also indicates the binding of both contaminants in the region that corresponds to O-H stretching. Moreover, in the case of As spectra, changes between 1016 and $1200 \mathrm{~cm}^{-1}$, connected to the $\mathrm{C}-\mathrm{O}$ stretching of alcohol esters and $-\mathrm{COOH}$ groups, can be observed. These could be associated with the adsorption ability of various As speciations via electrostatic interactions or ion exchange [28].

Scanning electron microscopy: SEM images of the fabricated $\mathrm{CH}-\mathrm{BB}$ are shown in Figure 2A-C. Two surface morphologies can be distinguished in CH-BB: coarse (Figure 2C) and stratified (Figure 2B). The coarse area had small pores, which were unevenly distributed, while the stratified surface had many grooves, furrows and tiny particles. The modification with chitosan changed the surface of raw biochar (Figure S2 and Figure 2).

Other physicochemical properties: The isoelectric point was found to be at $\mathrm{pH} 6.02$ (Figure S3). The results of the BET analysis are presented in Figure 2D. CH-BB had a 1.15fold higher surface area compared to $\mathrm{PM}-\mathrm{BC}$. The total pore volume in $\mathrm{CH}-\mathrm{BB}$ increased 1.10 times as compared to raw biochar. The modification of the biochar with chitosan also resulted in a decrease in pore size (Figure 2D).

A preliminary assessment of metals present in CH-BB was also performed (Table S2). There were less metals present in $\mathrm{CH}-\mathrm{BB}$ as compared to raw PM-BC. This is linked to the extensive washing of the beads after soaking them in $\mathrm{NaOH}$. Hence, most of the metals that were present in raw biochar were washed away. 

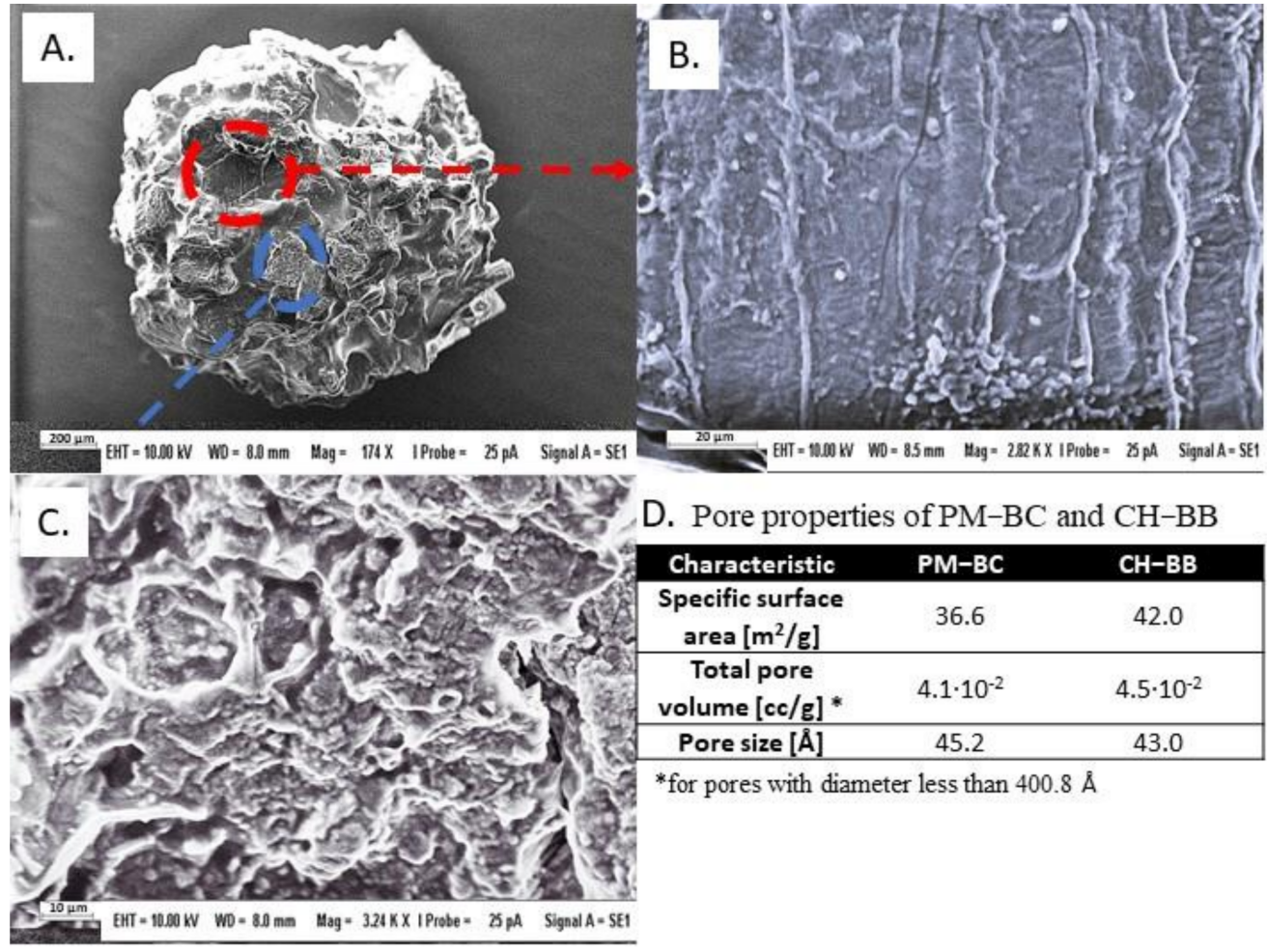

D. Pore properties of $\mathrm{PM}-\mathrm{BC}$ and $\mathrm{CH}-\mathrm{BB}$

\begin{tabular}{|c|c|c|}
\hline Characteristic & PM-BC & $\mathrm{CH}-\mathrm{BB}$ \\
\hline $\begin{array}{c}\text { Specific surface } \\
\text { area }\left[\mathrm{m}^{2} / \mathrm{g}\right]\end{array}$ & 36.6 & 42.0 \\
\hline $\begin{array}{c}\text { Total pore } \\
\text { volume }[\mathrm{cc} / \mathrm{g}]\end{array}$ & $4.1 \cdot 10^{-2}$ & $4.5 \cdot 10^{-2}$ \\
\hline Pore size $[\AA]$ & 45.2 & 43.0 \\
\hline
\end{tabular}

*for pores with diameter less than $400.8 \AA$

Figure 2. SEM images of chitosan-biochar beads (A-C); (D) pore properties of pig manure biochar (PM-BC) and chitosan-biochar beards (CH-BB).

\subsection{Adsorption onto $\mathrm{CH}-\mathrm{BB}$}

\subsubsection{Adsorption Potency}

Table 2 presents the comparison of the adsorption capacity between the raw and functionalized biochar. The modification of raw PM-BC resulted in an increase in its adsorption capacity in almost all cases. The highest increment was noticed for As (almost 6-fold), and the lowest was noticed for CIP (1.1-fold). However, the adsorption capacity towards $\mathrm{Pb}$ was slightly decreased.

Table 2. Adsorption capacity of the tested adsorbents, pH 6.0, $150 \mathrm{rpm}, 48 \mathrm{~h}$.

\begin{tabular}{ccc}
\hline & \multicolumn{2}{c}{ Adsorption Capacity (mg/g) } \\
\cline { 2 - 4 } Contaminant (Initial Concentration $(\mathrm{mg} / \mathrm{L}))$ & \multicolumn{1}{c}{ PM-BC } \\
\hline $\mathrm{Cd}(10)$ & & $1.49 \pm 0.06$ \\
\hline $\mathrm{Pb}(1)$ & & \\
\hline
\end{tabular}

Abbreviations: $\mathrm{PM}-\mathrm{BC} —$ pig manure biochar; $\mathrm{CH}-\mathrm{BB} —$ chitosan-biochar beads.

\subsubsection{Adsorption Isotherms}

Figure 3 presents the adsorption capacity of $\mathrm{CH}-\mathrm{BB}$ against the equilibrium concentration $\left(C_{e}\right)$ of pollutants. Plots of $\mathrm{Pb}$, As and CIP are concave isotherms (L-shaped), which suggests that when the concentration of the contaminants increased, the absorption was 
hindered as most of the adsorption sites were occupied. The isotherm for $\mathrm{Cd}$ is linear, which may indicate that this metal is distributed between the bulk solution phase and the interfacial phase. To better understand the relationship between the capacity of the adsorbent and targeted pollutants, three models, i.e., Langmuir, Freundlich and Redlich-Peterson, were fitted to the experimental data. The nonlinear equations that were used are presented in Table S4. The results are presented in Table 3. Based on the statistical parameters, the Redlich-Peterson model best described the adsorption ability of all four contaminants.
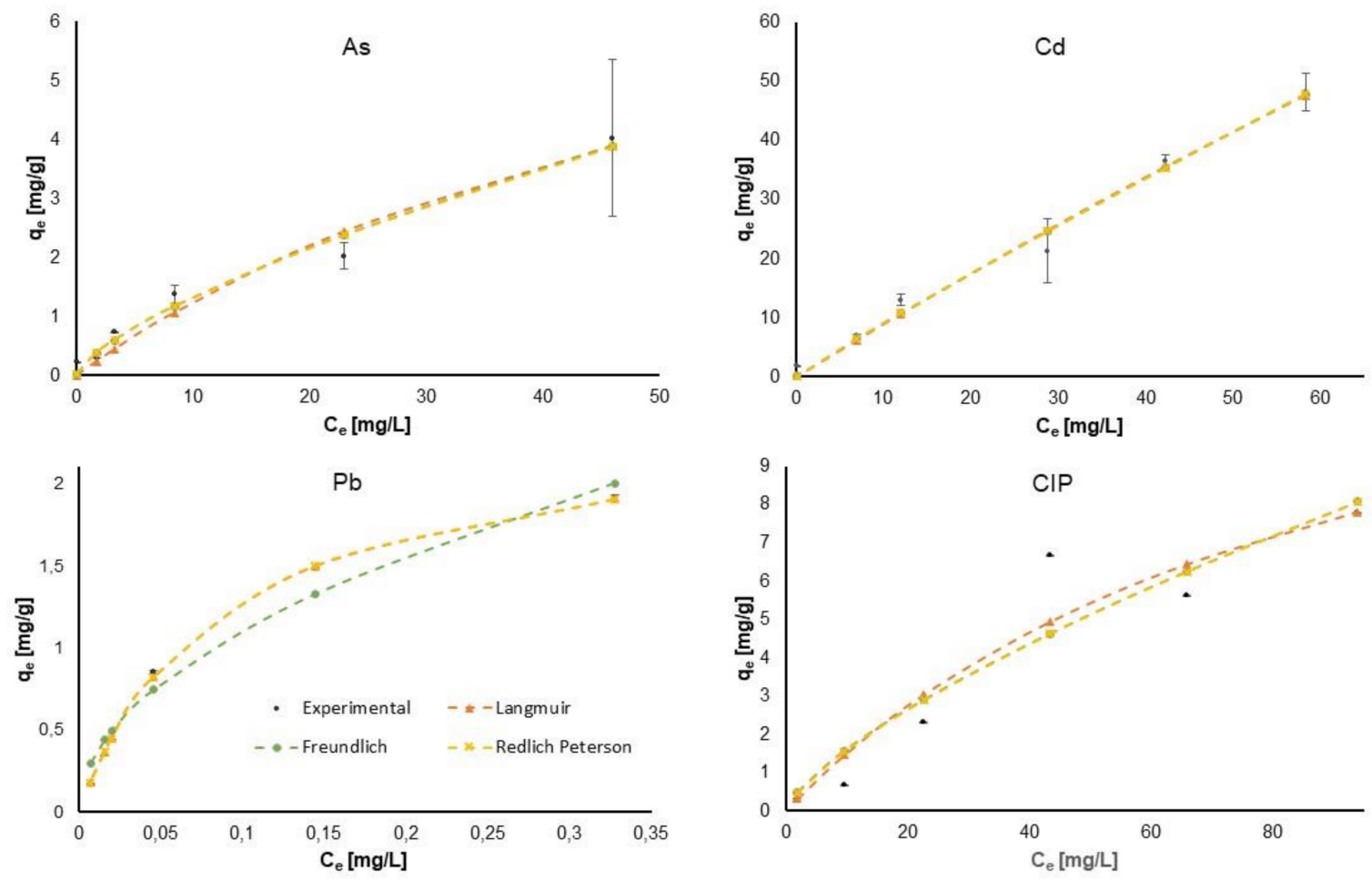

Figure 3. Adsorption isotherms of $\mathrm{As}, \mathrm{Cd}, \mathrm{Pb}$ and ciprofloxacin (CIP).

Table 3. Isotherm constants of ciprofloxacin (CIP) and heavy metals on chitosan-biochar beads.

\begin{tabular}{cccccc}
\hline Isotherm & Parameter & As & $\mathbf{C d}$ & $\mathbf{P b}$ & $\mathbf{C I P}$ \\
\hline & $q_{m}(\mathrm{mg} / \mathrm{g})$ & 9.59 & 451.99 & 2.42 & 15.55 \\
& $K_{L}(\mathrm{~L} / \mathrm{mg})$ & 0.01 & 0.002 & 11.16 & 0.012 \\
Langmuir & $R_{\mathrm{L}}$ & $0.57-1.00$ & $0.83-1.00$ & $0.04-0.31$ & $0.48-0.98$ \\
& $R^{2}$ & 0.96 & 0.99 & 1.00 & 0.91 \\
& $E$ & 0.07 & 3.80 & $0.29 \times 10^{-5}$ & 0.80 \\
& $\chi$ & 0.02 & $0.59 \times 10^{-7}$ & 1.00 & 0.94 \\
\hline \multirow{5}{*}{ Freundlich } & $n$ & 0.71 & 0.94 & 0.50 & 0.72 \\
& $K_{F}(\mathrm{~L} / \mathrm{mg})$ & 0.26 & 1.05 & 3.51 & 0.31 \\
& $R^{2}$ & 0.97 & 0.99 & 0.97 & 0.89 \\
& $E$ & 0.04 & 3.44 & $0.12 \times 10^{-3}$ & 0.97 \\
& $\chi$ & 0.80 & $0.26 \times 10^{-5}$ & 1.00 & 0.89 \\
\hline \multirow{5}{*}{ Redlich-Peterson } & $K_{R P}(\mathrm{~L} / \mathrm{g})$ & $1.06 \times 10^{4}$ & 7.86 & 26.76 & 12.16 \\
& $g$ & 0.29 & 0.07 & 1.00 & 0.28 \\
& $\left.a_{R T}(\mathrm{mg} / \mathrm{L})^{-\mathrm{g}}\right)$ & $4.06 \times 10^{4}$ & 6.46 & 11.15 & 38.99 \\
& $R^{2}$ & 0.97 & 0.99 & 1.00 & 0.89 \\
& $E$ & 0.04 & 3.45 & $0.29 \times 10^{-5}$ & 0.97 \\
& $\chi$ & 0.81 & $0.26 \times 10^{-5}$ & 1.00 & 0.89 \\
\hline
\end{tabular}




\subsubsection{Adsorption Kinetics}

Individual Adsorption Kinetics

Figure 4 presents the adsorption ability of the four pollutants against time. Individually, all contaminants exhibited a similar trend of adsorption onto CH-BB. As (Figure 4A) and CIP (Figure 4D) reached equilibrium in the first $3 \mathrm{~h}$ when tested individually or in the mixture. This can be attributed to the availability of active sites present on the adsorbent surface. In the case of $\mathrm{Pb}$ (Figure $4 \mathrm{C}$ ) and $\mathrm{Cd}$ (Figure $4 \mathrm{~B}$ ), around $24 \mathrm{~h}$ was required to attain equilibrium. This may be linked to the diffusion-controlled mechanism of metal adsorption [19]. The pore network of the adsorbent could hinder the intraparticle mass transfer of metals which could explain the delay in the adsorption equilibrium time.
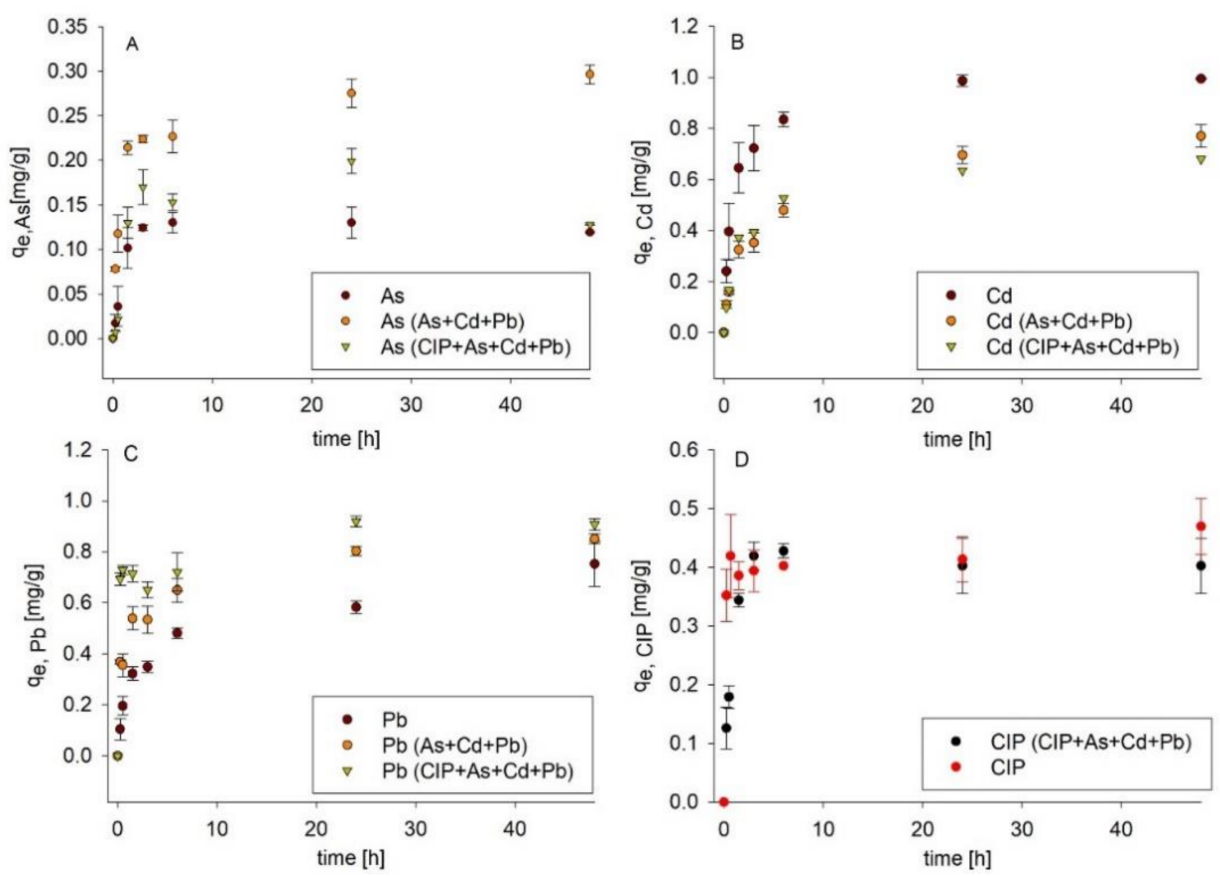

Figure 4. Kinetic curves of (A) As, (B) Cd, (C) Pb and (D) ciprofloxacin (CIP) individually and in mixtures.

Adsorption Kinetics for Pollutant Mixture

Cadmium: The adsorption ability of Cd decreased from $0.99 \pm 0.004$ to $0.75 \pm 0.004$ and $0.66 \pm 0.01 \mathrm{mg} / \mathrm{g}$ in the metal mixture and metal mixture with CIP, respectively. Hence, $\mathrm{Cd}$ could compete for adsorption sites with other inorganics and/or CIP, which led to a significant decrease in its removal ( $p$-value $<0.001)$.

Lead and arsenic: $\mathrm{Pb}$ exhibited the highest adsorption ability in the pollutant mixture. This can be associated with the co-precipitation of lead and arsenate as mimetite, which follows the reaction presented in Equation (8) [29]:

$$
5 \mathrm{~Pb}^{2+}+3 \mathrm{AsO}_{4}{ }^{3-}+\mathrm{Cl}^{-} \rightarrow \mathrm{Pb}_{5}\left(\mathrm{AsO}_{4}\right)_{3} \mathrm{Cl} \downarrow
$$

As a result, the 2-fold increase in the adsorption ability of As can be explained when other metals were present. The addition of CIP to the metal mixture led to the original adsorption ability of As (Figure 4A); however, it was still slightly higher than the removal of the metalloid individually. This can correspond to the chelation potency of CIP. Most probably, when a CIP-As/ $\mathrm{Pb}$ complex is formed, the reaction presented in Equation (8) is hindered due to the decrease in the concentration of free ions. To confirm if CIP can form a complex with $\mathrm{As} / \mathrm{Pb}$, the antibiotic and metalloid/metal were mixed in different ratios at $\mathrm{pH} 6$ and then scanned via a UV-Vis spectrophotometer. The absorption ability of CIP was quenched when As was added and enhanced in the presence of Pb (Figure S4); thus, this suggested that CIP was able to complex with $\mathrm{As}$ and $\mathrm{Pb}$ [27]. 
Ciprofloxacin: The adsorption ability of CIP was not altered by the presence of metals (Figure 4D). This may be attributed to different adsorption sites for organic and inorganic pollutants. Moreover, equilibrium was achieved faster when CIP was tested alone. This suggests that the presence of inorganic pollutants may have affected the mobility of the antibiotic.

\section{Kinetics Modeling}

To understand the kinetics of the adsorption mechanism of the tested pollutants, three adsorption models (Figure 5), i.e., pseudo-first order, pseudo-second order, Elovich and one diffusion model (intraparticle diffusion model, Figure 6), were tested. To avoid common mistakes in the adsorption model calculations, the nonlinear method was used [30]; the equations are presented in Table S4. The results of the calculations are shown in Table 4.

Arsenic: Based on various error functions, the adsorption ability of As onto CH-BB was best fitted by the pseudo-first order model in all three cases, followed by the pseudo-second order model. Hence, one can assume that the mechanism of As adsorption may include both physio- and chemisorption. The calculated adsorption capacity values for both models are comparable with the experimental values (Table 4).

The simultaneous removal of inorganic pollutants resulted in a slightly reduced rate constant for the pseudo-first and pseudo-second order models. On the other hand, the adsorption ability of As in the inorganic mixture resulted in a 2-fold increase (Table 4). This may be associated with an additional removal mechanism, which is the co-precipitation of As with $\mathrm{Pb}$ (Equation (8)). The addition of CIP to the mixture resulted in worsening the statistical parameters for both models. Hence, this suggests that potential CIP-As complexation might have disturbed the adsorption/precipitation processes.

Cadmium: The pseudo-second order and Elovich models exhibited the best fit for the $\mathrm{Cd}$ adsorption ability onto $\mathrm{CH}-\mathrm{BB}$ (Table 4). Hence, this may suggest that chemisorption was the main mechanism of $\mathrm{Cd}$ uptake. The calculated adsorption capacities (pseudosecond order) match the experimental data (Table 4 ). The addition of inorganic pollutants led to decline in $q_{e}$. Additionally, the constant rate $\left(k_{2}\right)$ decreased 2.6-fold when the metal mixture was tested. This can be associated with competition over sorption sites between the present elements.

Interestingly, once CIP was added to the mix, the constant rate increased 2-fold, while the adsorption capacity for $\mathrm{Cd}$ still decreased. A similar trend can be observed for the initial constant rate $(\alpha)$ in the Elovich model. One can assume that potential CIP-Cd complexes have a higher affinity towards the aqueous phase, while $\mathrm{As}$ and $\mathrm{Pb}$ undergo co-precipitation or CIP complexation; hence, there are fewer free inorganic contaminants that are competing over sorption sites. Moreover, the addition of pollutants to the solution increased the desorption constant $(\beta)$.

As it can be seen in Table 4, intraparticle diffusion was involved in the adsorption process of $\mathrm{Cd}$ onto $\mathrm{CH}-\mathrm{BB}$. To further investigate the potential adsorption mechanism, the correlation between $q_{t}$ and $t^{1 / 2}$ was plotted, and it is shown in Figure $6 \mathrm{~A}$. The plots present at least two linear regions; hence, one can assume that the process was controlled by a multistep mechanism. Moreover, the first plot crosses the origin in all three cases; thus, this suggests that intraparticle diffusion was a rate-controlling factor. With the addition of other pollutants, the intraparticle diffusion constant slightly declined. Furthermore, the lower value of the thickness of the boundary layer constant $(I)$, when the mixture of pollutants was tested, suggests that it has a lower effect on the limiting boundary layer compared to the $\mathrm{Cd}$ tests alone. 


\section{PSEUDO-FIRSTORDER}
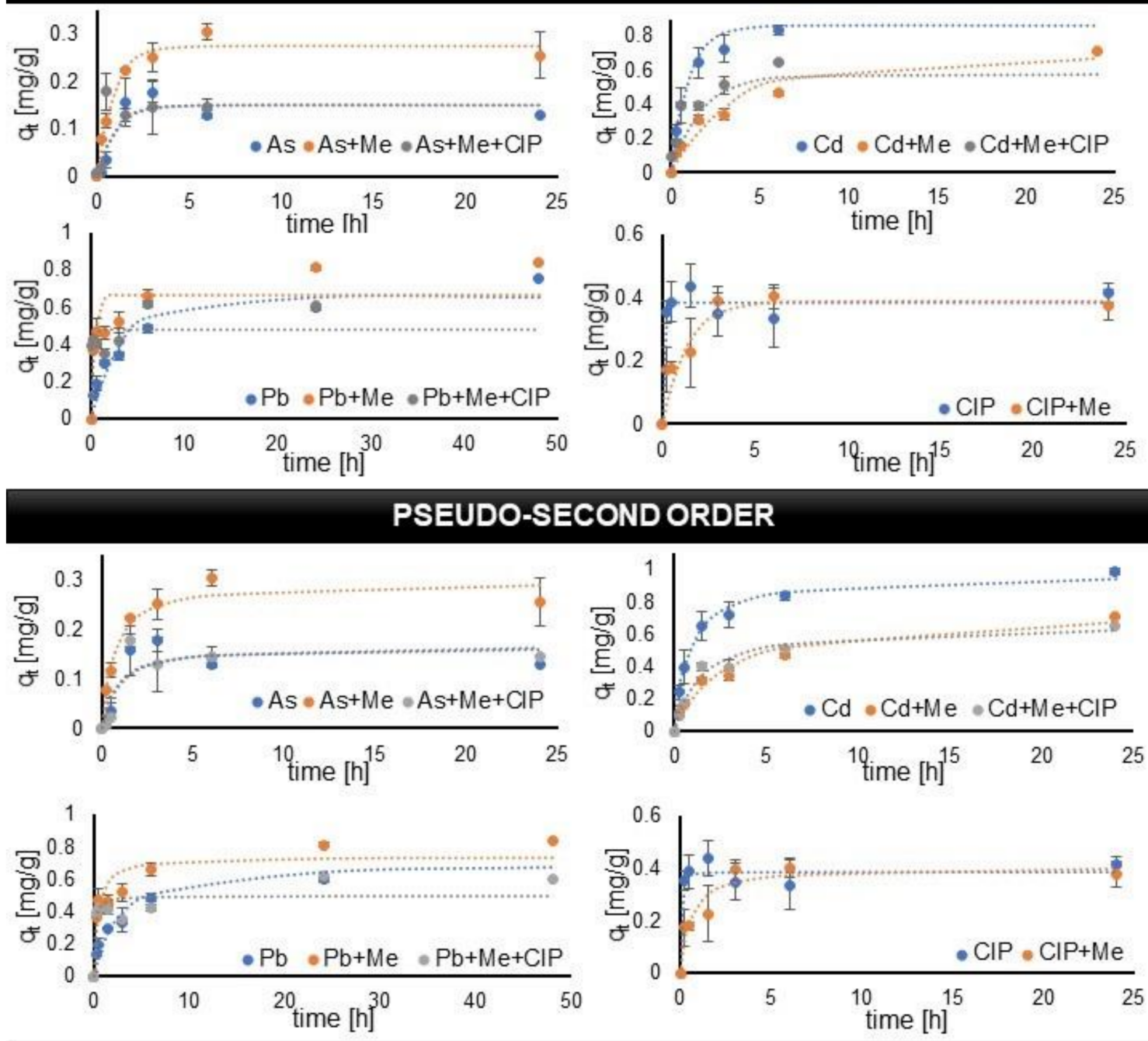

\section{ELOVICH}
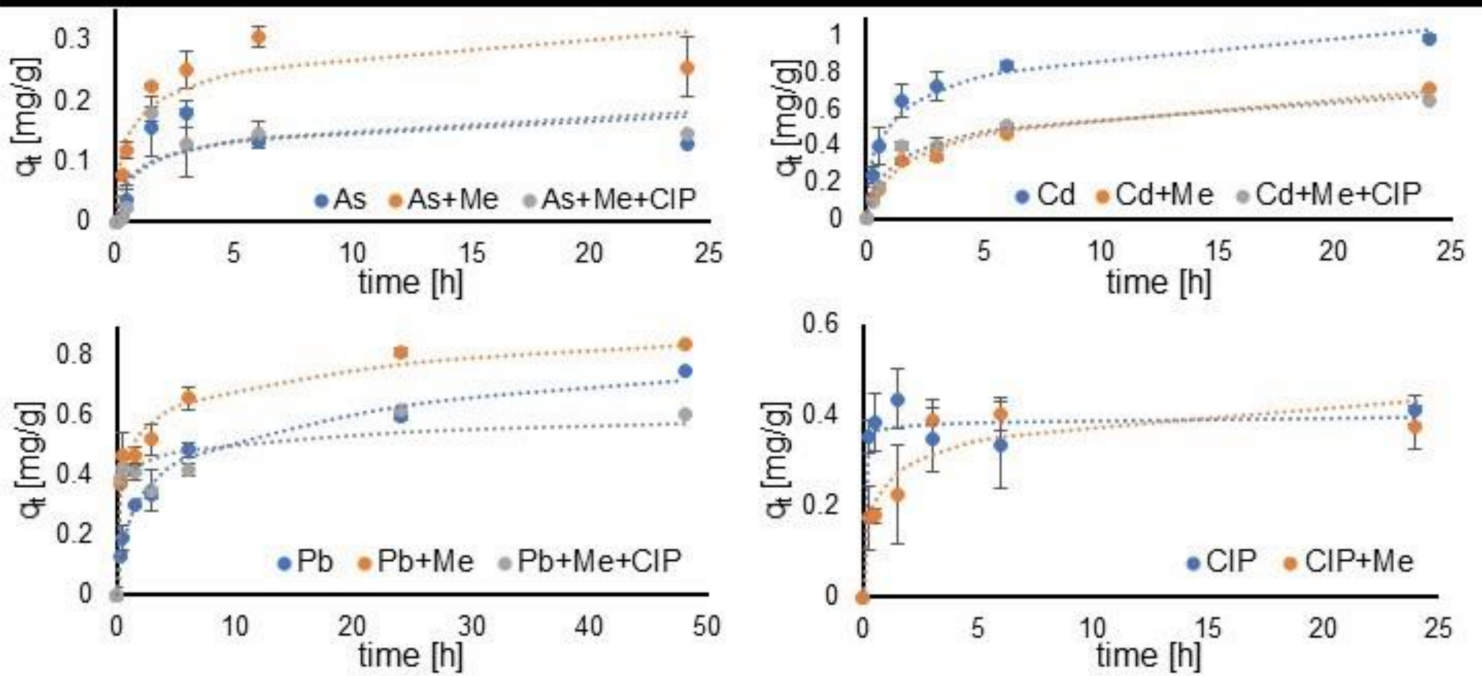

Figure 5. Kinetic curves of adsorption models, i.e., pseudo-first order, pseudo-second order and Elovich, for the tested pollutants on $\mathrm{CH}-\mathrm{BB}$. 
Table 4. Kinetic parameters of the pollutants' adsorption onto chitosan-biochar beads.

\begin{tabular}{|c|c|c|c|c|c|c|c|c|c|c|c|c|c|c|c|c|c|c|c|c|c|c|}
\hline & \multirow{2}{*}{ Pollutant(s) } & \multirow{2}{*}{$q_{e, \exp }$} & \multicolumn{5}{|c|}{ Pseudo-First Order } & \multicolumn{5}{|c|}{ Pseudo-Second Order } & \multicolumn{5}{|c|}{ Elovich } & \multicolumn{5}{|c|}{ Intraparticle Diffusion } \\
\hline & & & $k_{1}$ & $q_{e, m}$ & $\mathbf{R}^{2}$ & $\mathrm{E}$ & $x$ & $k_{2}$ & $q_{e, m}$ & $\mathbf{R}^{2}$ & $\mathrm{E}$ & $x$ & $\alpha$ & $\beta$ & $\mathbf{R}^{2}$ & $\mathrm{E}$ & $x$ & $k_{p}$ & $I$ & $\mathbf{R}^{2}$ & $\mathrm{E}$ & $x$ \\
\hline \multirow[b]{2}{*}{ As } & Individually & $0.15 \pm 0.02$ & 1.10 & 0.15 & 0.81 & $0.68 \times 10^{-5}$ & 0.99 & 8.47 & 0.17 & 0.70 & $0.11 \times 10^{-4}$ & 0.99 & 0.64 & 36.50 & 0.51 & $0.18 \times 10^{-4}$ & 0.99 & 0.020 & 0.069 & 0.26 & $0.26 \times 10^{-4}$ & 0.99 \\
\hline & Metal mixture & $0.27 \pm 0.02$ & 0.96 & 0.27 & 0.96 & $0.25 \times 10^{-5}$ & 0.99 & 5.41 & 0.30 & 0.93 & $0.41 \times 10^{-3}$ & 1.00 & 2.01 & 22.18 & 0.77 & $0.14 \times 10^{-2}$ & 0.99 & 0.035 & 0.14 & 0.50 & $0.31 \times 10^{-2}$ & 0.99 \\
\hline \multirow{3}{*}{$\mathrm{Cd}$} & Individually & $0.99 \pm 0.004$ & 1.00 & 0.87 & 0.93 & $0.45 \times 10^{-4}$ & 0.99 & 1.28 & 0.98 & 0.99 & $0.76 \times 10^{-5}$ & 1.00 & 3.49 & 5.98 & 0.97 & $0.18 \times 10^{-4}$ & 0.99 & 0.15 & 0.35 & 0.80 & $0.12 \times 10^{-3}$ & 0.99 \\
\hline & Metal mixture & $0.75 \pm 0.04$ & 0.27 & 0.67 & 0.90 & $0.37 \times 10^{-2}$ & 0.99 & 0.49 & 0.75 & 0.95 & $0.18 \times 10^{-2}$ & 0.99 & 0.54 & 6.37 & 0.99 & $0.44 \times 10^{-3}$ & 0.99 & 0.13 & 0.10 & 0.96 & $0.14 \times 10^{-2}$ & 0.99 \\
\hline & Metal mixture + CIP & $0.66 \pm 0.01$ & 0.58 & 0.58 & 0.92 & $0.27 \times 10^{-2}$ & 0.99 & 1.08 & 0.66 & 0.97 & $0.11 \times 10^{-2}$ & 1.00 & 0.95 & 7.69 & 0.96 & $0.14 \times 10^{-2}$ & 0.99 & 0.12 & 0.15 & 0.82 & $0.59 \times 10^{-2}$ & 0.99 \\
\hline \multirow[t]{2}{*}{$\mathrm{Pb}$} & Metal mixture & $0.83 \pm 0.01$ & 2.50 & 0.67 & 0.53 & 0.01 & 0.99 & 3.36 & 0.74 & 0.74 & $0.89 \times 10^{-2}$ & 0.99 & 16.47 & 10.79 & 0.95 & $0.14 \times 10^{-2}$ & 0.99 & 0.072 & 0.40 & 0.92 & $0.27 \times 10^{-2}$ & 0.99 \\
\hline & Metal mixture + CIP & $0.61 \pm 0.01$ & 6.37 & 0.48 & 0.33 & $0.76 \times 10^{-2}$ & 0.99 & 20.39 & 0.50 & 0.41 & $0.55 \times 10^{-2}$ & 0.99 & 566.01 & 23.16 & 0.71 & $0.35 \times 10^{-2}$ & 0.99 & 0.039 & 0.36 & 0.85 & $0.20 \times 10^{-2}$ & 0.99 \\
\hline \multirow{2}{*}{$\mathrm{CIP}-$} & Individually & $0.37 \pm 0.03$ & 10.07 & 0.38 & 0.71 & $0.10 \times 10^{-4}$ & 0.99 & 175 & 0.39 & 0.70 & $0.11 \times 10^{-4}$ & 1.00 & $1.25 \times 10^{19}$ & 131.07 & 0.68 & $0.12 \times 10^{-4}$ & 0.99 & 0.006 & 0.37 & 0.7 & $0.11 \times 10^{-4}$ & 0.99 \\
\hline & Metal mixture + CIP & $0.39 \pm 0.01$ & 0.77 & 0.39 & 0.74 & $0.26 \times 10^{-2}$ & 0.99 & 4.51 & 0.41 & 0.84 & $0.16 \times 10^{-2}$ & 0.99 & 4.40 & 17.47 & 0.78 & $0.22 \times 10^{-2}$ & 0.99 & 0.048 & 0.20 & 0.59 & $0.42 \times 10^{-2}$ & 0.99 \\
\hline
\end{tabular}

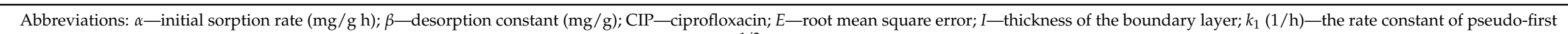

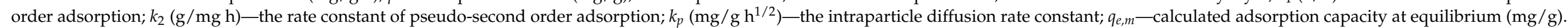


A.

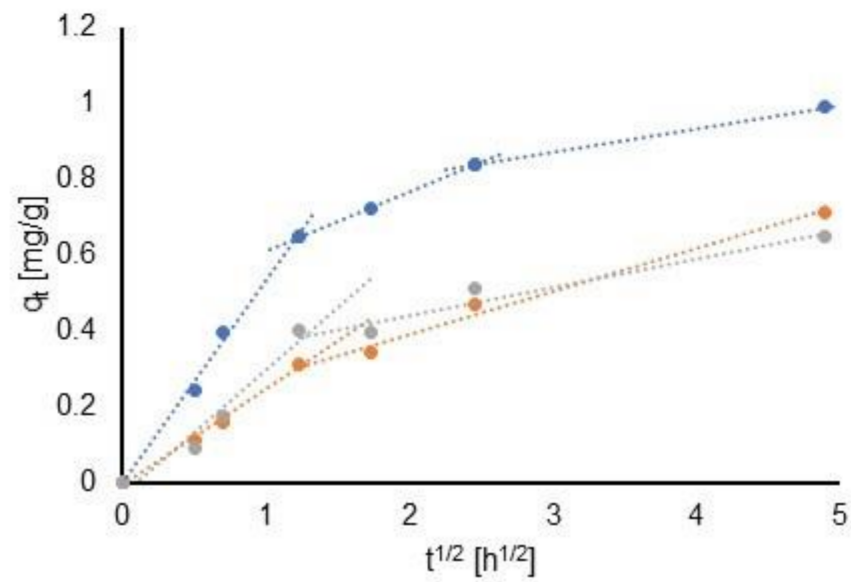

- $\mathrm{Cd}$

- $\mathrm{Cd}+\mathrm{Me}$

- $\mathrm{Cd}+\mathrm{Me}+\mathrm{CIP}$

......... Linear $(\mathrm{Cd})$

......... Linear $(\mathrm{Cd}+\mathrm{Me})$

......... Linear $(\mathrm{Cd}+\mathrm{Me}+\mathrm{ClP})$

B.

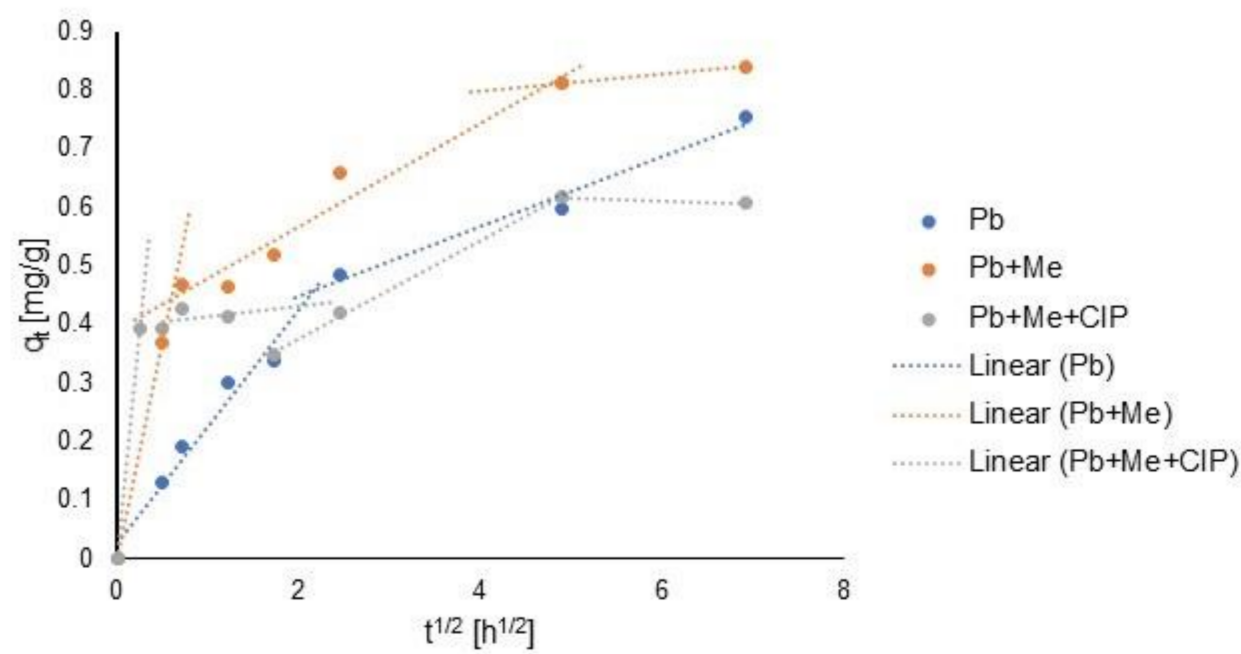

Figure 6. Kinetic curves of intraparticle diffusion model for $\mathrm{Cd}(\mathbf{A})$ and $\mathrm{Pb}(\mathbf{B})$ onto $\mathrm{CH}-\mathrm{BB}$.

Lead: The adsorption ability of lead, alone and in the mixture, onto $\mathrm{CH}-\mathrm{BB}$ is best described by the Elovich model, which suggests that the main mechanism might have involved chemisorption. The initial sorption rate $(\alpha)$ increased when other inorganics (20-fold) and CIP (700-fold) were added. However, in the latter case, the value needs to be taken cautiously and rather as a rough estimate due to the worse model fit $\left(R^{2}=0.71\right)$ as compared to the other cases $\left(R^{2} 0.95-0.99\right)$.

When $\mathrm{Pb}$ was tested alone, the values of statistical parameters for the pseudo-second order model may have also been an indication for chemisorption. However, the $\mathrm{R}^{2}$ for the pseudo-first order model was also rather high; hence, this suggests that physical adsorption might also have been involved. Interestingly, once the other pollutants were added (CIP especially), neither the pseudo-second order nor pseudo-first order model could be applied $\left(\mathrm{R}^{2}\right.$ 0.41-0.74). This may be associated with the additional removal mechanisms, i.e., the co-precipitation with As (Equation (8)).

The high values of the statistical parameters for the intraparticle diffusion model present a good fit for $\mathrm{Pb}$ adsorption. The plot $q_{t}$ versus $t^{1 / 2}$ presented in Figure $6 \mathrm{~B}$ confirms that the $\mathrm{Pb}$ adsorption ability is controlled by a multistep mechanism. The first plots crossed the origin; hence, similar to $\mathrm{Cd}$, adsorption of $\mathrm{Pb}$ is governed by intraparticle diffusion. The intraparticle diffusion rate constant declined, once the pollutants were added; the presence of CIP resulted in an almost 3-fold decrease. Hence, the fluoroquinolone antibiotic may have a greater influence on $\mathrm{Pb}$ adsorption mechanisms than on $\mathrm{Cd}$. Another difference between these two divalent ions' behavior can be seen in the thickness of the boundary 
layer constant change. Once the other pollutants were added to the mixture, $I$ increased 2-fold for $\mathrm{Pb}$, while it decreased for $\mathrm{Cd}$. This suggests that in the contaminant mixture, $\mathrm{Pb}$ is more affected by the thickness of the boundary layer, as compared to $\mathrm{Cd}$.

Ciprofloxacin: In the case of CIP (alone and mixture), three models (pseudo-first order, pseudo-second order and Elovich) have similar values for all statistical parameters. However, a slightly better fit can be seen for the pseudo-second order model $\left(\mathrm{R}^{2} 0.70-0.84\right)$, followed by the pseudo-first order $\left(R^{2} 0.71-0.74\right)$ and Elovich models $\left(R^{2} 0.68-0.78\right)$. Hence, this suggests that the adsorption ability of CIP included both chemisorption and physisorption. The calculated adsorption capacity is comparable with the experimental values. The addition of inorganic pollutants resulted in a decrease in the rate constant in all three models. Hence, this confirms that the presence of metals does not interfere with the amount of antibiotic that adsorbs onto CH-BB, but it may negatively affect CIP's mobility.

\subsubsection{Co-Adsorption of CIP and Heavy Metals}

To further investigate the influence of organic and inorganic contaminants on their removal via $\mathrm{CH}-\mathrm{BB}$, a co-adsorption test was performed. The metal/metalloid concentrations remained constant $(4 \mathrm{mg} / \mathrm{L})$, while the CIP concentration ranged between 0.5 and $20 \mathrm{mg} / \mathrm{L}$. The results are presented in Figure 7. The increasing CIP concentration generally did not have a significant influence on the $\mathrm{Cd}(p$-value $=0.99)$ and $\mathrm{As}(p$-value $=0.053)$ adsorption capacities. The adsorption ability of $\mathrm{Pb}$ was enhanced when the initial concentration of $\mathrm{CIP}$ and $\mathrm{Pb}$ was almost equal (5:4). After this point, $\mathrm{Pb}$ removal was constant ( $p$-value $>0.05$ ). The results suggest that inorganic pollutants occupy different adsorption sites compared to CIP.

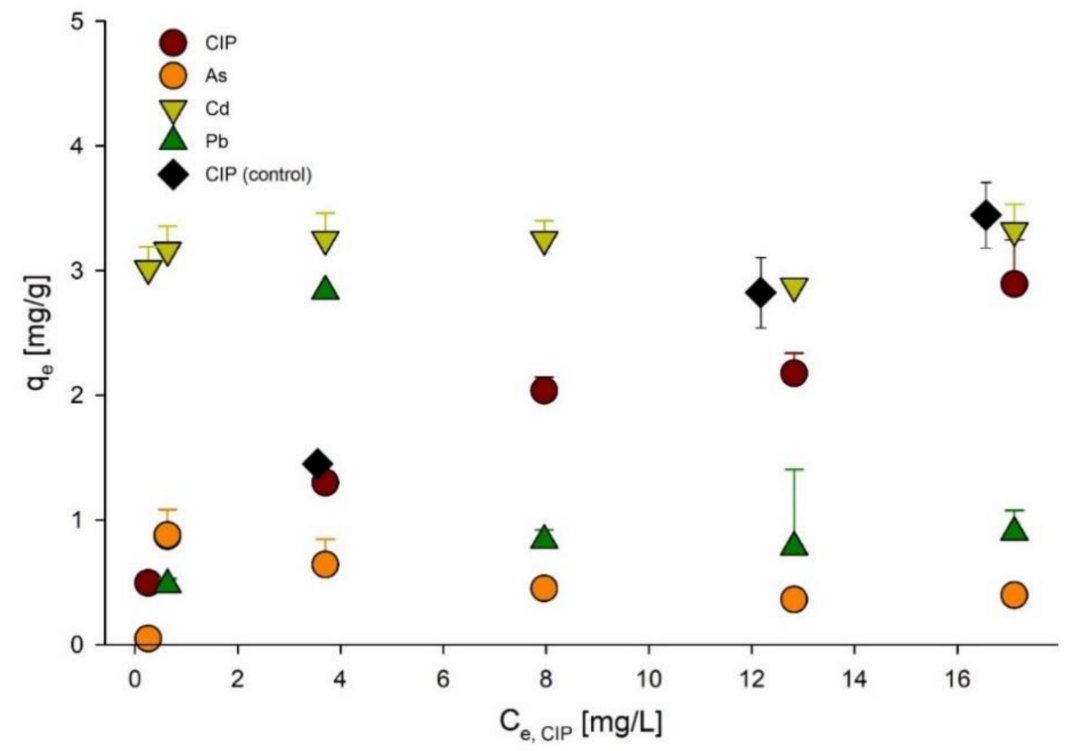

Figure 7. Co-adsorption of ciprofloxacin (CIP) and heavy metals; CIP concentration 0.5-20 mg/L, heavy metals $4 \mathrm{mg} / \mathrm{L}$.

\subsubsection{Test with Real Wastewater}

The results of the removal efficiency test are presented in Table 5. Pb removal was almost $100 \%$ for all tested adsorbents. In this study, in the case of As and Cd, CH-BB exhibited a better removal efficiency than raw biochar and commercial GAC. Only CH-BB could remove As (4.5\%). More than $90 \%$ of cadmium was removed from the wastewater. Moreover, adsorption of Cd increased 2-fold and 3-fold when compared with PM-BC and GAC, respectively. However, the adsorption ability of CIP followed a different order; almost $90 \%$ of CIP was removed by GAC, whereas the generated adsorbent exhibited the lowest removal efficiency (35\%). Overall, $\mathrm{CH}-\mathrm{BB}$ proved to be a suitable adsorbent for simultaneous heavy metal and CIP removal from wastewater. 
Table 5. Comparison of removal efficiency between different adsorbents.

\begin{tabular}{ccccc}
\hline Adsorbent & As (\% Removed) & Cd (\% Removed) & Pb (\% Removed) & CIP (\% Removed) \\
\hline CH-BB & $4.50 \pm 0.76$ & $92.86 \pm 0.68$ & $99.99 \pm 0.03$ & $34.95 \pm 4.03$ \\
\hline PM-BC & NR & $42.54 \pm 6.25$ & $99.74 \pm 0.07$ & $43.57 \pm 6.71$ \\
\hline GAC & NR & $31.20 \pm 0.00$ & $99.52 \pm 0.12$ & $87.93 \pm 6.71$ \\
\hline
\end{tabular}

Abbreviations: CH-BB, chitosan-biochar beads; PM-BC, pig manure biochar; GAC, granulated active carbon; $\mathrm{CIP}$ ciprofloxacin; NR, no removal.

\section{Discussion}

\section{1. $\mathrm{CH}-\mathrm{BB}$ Generation}

As shown in Section 3.1., the modification of the biochar surface with chitosan led to an increased sorption capacity for the targeted pollutants. Similar results were reported previously. For example, Zhou et al. (2013) reported chitosan modification of four types of biochar (bamboo, sugarcane bagasse, hickory wood and peanut hull) and their efficiency in removing $\mathrm{Pb}^{2+}, \mathrm{Cu}^{2+}$ and $\mathrm{Cd}^{2+}$ from water [19]. Chitosan-bamboo biochar removed $\mathrm{Pb}$ the most efficiently, whereas chitosan-sugarcane bagasse biochar was the best option to remove Cd [19]. Nevertheless, almost all modified types of biochar removed metals more successfully than raw materials, which is consistent with the results obtained in this study (Table 2).

Additionally, the report of Afzal et al. (2018) demonstrated that chitosan-pomelo biochar hydrogel beads efficiently adsorbed $76 \%$ of CIP, whereas raw pomelo biochar was able to adsorb only $6 \%$ of the antibiotic [24]. As it can be seen, the sorption ability of CIP was much higher than that obtained in this study (Table 2). This can be related to the biochar's feedstock, which strongly influences the pollutants' adsorption properties via different functional groups that could potentially attract contaminants (Figure S1) [19,24].

\subsection{Adsoprtion Isotherms}

As it can be seen in Table 3, the three-parameter Redlich-Peterson model best described the adsorption ability of the targeted contaminants. This isotherm model combines the characteristics of the Langmuir and Freundlich models, and the additional parameter may be responsible for the better fit [31]. The value of the exponent $g$ of the RedlichPeterson model can offer more insight into the adsorption process. When $g=1$, the process follows the Langmuir model; however, when $g$ equals zero, the Redlich-Peterson equation (Table S4) becomes a linear isotherm, corresponding to Henry's law equation. The constant $g$ of the $\mathrm{Pb}$ isotherm is equal to 1.00, which indicates the chemisorption represented by the Langmuir model [32]. Moreover, the isotherms of the Redlich-Peterson and Langmuir models exactly overlapped (Figure 3). These results can be associated with the heterogeneity of the physicochemical properties of biochar and $\mathrm{CH}-\mathrm{BB}$, such as the surface charge or carbon crystallinity [33]. Moreover, lead sorption may be influenced by the coordination of chitosan amine groups, which is usually consistent with Langmuir adsorption [19].

In the case of As and CIP, the $g$ constant is around 0.3 (Table 3). Additionally, the Redlich-Peterson and Freundlich isotherms of CIP and As exactly overlapped, suggesting that the latter may also describe their adsorption process. The constant $g$ for the $\mathrm{Cd}$ adsorption data is close to zero. Furthermore, the isotherm is linear (Figure 3), implying that the sorption process followed Henry's law equation [30].

\subsection{Adsoprtion in Pollutant Mixture}

Competitive adsorption could be observed only between the inorganic contaminants, but not between organic and inorganic compounds. This is consistent with the work of Liu et al. (2018), where the co-adsorption ability of heavy metal ions and fluoroquinolones on a functionalized ferromagnetic microsphere was tested [34]. In their study, the inorganic contaminants did not alter the adsorption of the antibiotics and vice versa. This may be associated with the speciation of the tested pollutants; $\mathrm{Cd}$ and $\mathrm{Pb}$ are present as divalent 
cations, As is mostly present as $\mathrm{H}_{2} \mathrm{AsO}_{4}{ }^{-}$and CIP is a zwitterion (CIP $\left.{ }^{ \pm}\right)$. Thus, the sorption of the targeted pollutants may follow various mechanisms; $\mathrm{Cd} / \mathrm{Pb}$ ions probably bind in a different manner (chelation via - $\mathrm{OH},-\mathrm{NH}_{2}$ ) than As/CIP (surface complexation reaction or ion exchange) $[19,24,28,35,36]$. Moreover, there may be antagonistic interactions between negatively charged As and other anions in the solution (in this study: $\mathrm{SO}_{4}{ }^{2-}, \mathrm{NO}_{3}{ }^{-}$and $\mathrm{Cl}^{-}$from $\mathrm{Cd}^{2+}$ and $\mathrm{Pb}^{2+}$ stock solutions), which hindered the As sorption ability [35].

Furthermore, the structure of $\mathrm{CIP}$ contains a benzene ring with strong electron-withdrawing groups, i.e., N-heteroaromatic ring and fluoride atom (Table 2). This makes it susceptible to $\pi-\pi$ electron donor-acceptor interactions [24]. The presence of oxygen/hydrogen-containing groups in $\mathrm{CIP}\left(-\mathrm{OH},-\mathrm{NH}_{2},-\mathrm{COOH}\right), \mathrm{CH}-\mathrm{BB}\left(-\mathrm{OH},-\mathrm{NH}_{2},-\mathrm{COOH}\right)$ or $\mathrm{H}_{2} \mathrm{AsO}_{4}{ }^{-}\left({ }^{-} \mathrm{OH}\right)$ may be responsible for the removal of the mentioned pollutants via hydrogen bonds created between them and $\mathrm{CH}-\mathrm{BB}$. Additionally, the pore network in $\mathrm{CH}-\mathrm{BB}$ may act as a size-exclusive adsorbent. The inorganic ions are much smaller molecules than the antibiotic, and hence they can penetrate pores easily [20].

As mentioned above, the divalent cations tested in this study exhibit similar mechanisms of sorption. Moreover, there are reports that prove that both $\mathrm{Cd}$ and $\mathrm{Pb}$ have the potency to co-precipitate with arsenate $[29,37]$. Hence, one may assume that the presence of $\mathrm{Cd}, \mathrm{Pb}$ and As would lead to an enhancement in the sorption ability of all tested metal(loid)s. However, in the case of this study, this can be seen only for $\mathrm{Pb}$ and $\mathrm{As}$, not for Cd (Figure 4). A similar situation was observed in the study of Deng et al. (2019), who investigated the co-precipitation of $\mathrm{Pb}, \mathrm{Cd}$ and $\mathrm{Cu}$ with an orthophosphate group (analogue of arsenate) on chloro-phosphate-impregnated biochar [38]. This behavior was explained by a difference in the solubility constant $\left(K_{s p}\right)$ : the lower the $K_{s p}$ constant, the easier the formation of precipitates. In the case of $\mathrm{Pb}_{5}\left(\mathrm{PO}_{4}\right)_{3} \mathrm{Cl}$ and $\mathrm{Cd}_{5}\left(\mathrm{PO}_{4}\right) \mathrm{Cl}$, the $K_{s p}$ was $10^{-84.4}$ and $10^{-49.66}$, respectively [38]. Thus, based on chemical similarities between arsenate and phosphate, it can be assumed that the analogue relation might have occurred in the case of this study. Additionally, the metal ions with higher electronegativity would tend to present higher specific adsorption abilities due to their higher affinity towards polar functional groups on CH-BB [38,39]. This would provide an additional explanation of the superior adsorption ability of $\mathrm{Pb}$ in the pollutant mixture (Figures 4 and 7, Table S5).

The CIP chelation potency could have also affected the adsorption ability of inorganic contaminants and vice versa. Even though there was no evident competition between CIP and inorganic pollutants over the sorption sites, the adsorption ability of CIP was slower in the mixture than alone (Figure 4). This may be explained by the alteration in CIP's mobility by the divalent ions [40]. Moreover, $\mathrm{Pb}$ has the highest complexation affinity with CIP amongst all tested metals [41], which may have significantly influenced the adsorption/precipitation mechanism.

\section{Conclusions}

All tested types of raw biochar were able to remove all targeted pollutants. However, their adsorption capacities depended on the type of biochar and the pollutant. Based on the data, PM-BC was selected for its further modification. The fabricated CH-BB demonstrated an increased adsorption capacity towards all targeted pollutants, in contrast to PM-BC, except for $\mathrm{Pb}$, which decreased slightly. The comparison of the simultaneous removal efficiency of the targeted pollutants in real wastewater between CH-BB, PM-BC and GAC showed that $\mathrm{CH}-\mathrm{BB}$ had a much better performance than the rest of the tested materials.

Adsorption isotherms revealed that all four pollutants were best fitted by the RedlichPeterson model. The kinetic and co-adsorption studies of the targeted pollutants revealed the following mechanisms:

- Arsenic: Physisorption was the main sorption mechanism. In the presence of other heavy metals, the adsorption capacity increased 2-fold due to co-precipitation of $\mathrm{As}$ and $\mathrm{Pb}$ (mimetite). The potential complexation between CIP and As resulted in decreased sorption of the metalloid. 
- Cadmium: Chemisorption was the main sorption mechanism, where intraparticle diffusion was a rate-controlling factor. The addition of other pollutants resulted in a decreased adsorption ability of $\mathrm{Cd}$, suggesting (1) competition over adsorption sites between elements, and (2) CIP-Cd complex formation, which has a higher affinity towards the aqueous phase.

- Lead: Intraparticle diffusion was a rate-controlling factor during the sorption process. Chemisorption was the main sorption mechanism when $\mathrm{Pb}$ was tested alone. The addition of other pollutants resulted in sorption disturbance due to (1) co-precipitation of $\mathrm{Pb}$ with $\mathrm{As}$, and (2) CIP- $\mathrm{Pb}$ complex formation (less free $\mathrm{Pb}^{2+}$ to adsorb onto $\mathrm{CH}-\mathrm{BB}$ ). Moreover, CIP exhibited the greatest influence on the $\mathrm{Pb}$ adsorption ability amongst the tested inorganic pollutants.

- Ciprofloxacin: CIP adsorption involved both chemi- and physisorption. The presence of inorganic pollutants did not influence the antibiotic adsorption ability but negatively affected its mobility.

Overall, the co-existence of inorganic and/or organic pollutants may significantly influence their sorption ability; in the present study, it exhibited mostly an antagonistic effect via competitive interactions ( $\mathrm{Cd}, \mathrm{Pb}, \mathrm{As})$ or complexation (CIP-As, $\mathrm{CIP}-\mathrm{Pb}, \mathrm{CIP}-\mathrm{Cd})$. However, in some cases, co-contamination may result in an enhanced removal potency, for example, via co-precipitation (As-Pb). Thus, the development of novel methods or improvement in existing techniques for water treatment should take into consideration the potential impact of co-contaminates on the removal of the targeted pollutants.

Supplementary Materials: The following are available online at https:/ /www.mdpi.com/article/ 10.3390/w13192768/s1, Description of adsorption of contaminants onto raw biochar and effect of $\mathrm{pH}$ on adsorption onto $\mathrm{CH}-\mathrm{BB}$, Figure S0: Influence of $\mathrm{pH}$ on adsorption of ciprofloxacin (CIP) and heavy metals, Figure S1: FTIR spectra of tested biochars, Figure S2: SEM images of pig manure biochar, Figure S3: The isoelectric point of CH-BB, Figure S4: UV-Vis absorption spectra of ciprofloxacin (CIP) in the presence of different concentrations of A. As; B. Pb, Table S1: Production details of used biochars, Table S2: Metal concentrations leached from biochars and CH-BB, Table S3: Adsorption capacity of the tested adsorbents, Table S4: Kinetic and adsorption models and their parameters, Table S5: Comparison of targeted heavy metals.

Author Contributions: A.C.: methodology, investigation, validation, visualization, formal analysis, writing — original draft; Z.M.: methodology, supervision, writing—review and editing; T.R.: methodology, conceptualization, supervision, writing—review and editing; H.R.: resources, supervision, project administration; S.K.B.: resources, writing-review and editing, supervision; E.K.: investigation, resources; P.D.: supervision, resources, writing —review and editing, project administration. All authors have read and agreed to the published version of the manuscript.

Funding: The authors are sincerely thankful to the Natural Sciences and Engineering Research Council of Canada (Discovery Grant 355254 and NSERC Strategic Grant) and MITACS Globalink Internship Award for financial assistance.

Institutional Review Board Statement: Not applicable.

Informed Consent Statement: Not applicable.

Data Availability Statement: Data are available from the authors on request.

Acknowledgments: We would like to thank Pratik Kumar for his help with SEM imaging and Joseph Sebastian for his help with biochar beads preparation. The authors are sincerely thankful to Sven Andreas Högfeldt for his help with ICP-MS analysis and Stéphane Moïse for his assistance with LC-MS/MS analysis. We would like to kindly thank Gayatri Suresh for conducting a third-person reading and suggesting corrections to the manuscript.

Conflicts of Interest: The authors declare no conflict of interest. 


\section{References}

1. Bolisetty, S.; Peydayesh, M.; Mezzenga, R. Sustainable technologies for water purification from heavy metals: Review and analysis. Chem. Soc. Rev. 2019, 48, 463-487. [CrossRef]

2. Pobi, K.K.; Satpati, S.; Dutta, S.; Nayek, S.; Saha, R.N.; Gupta, S. Sources Evaluation and Ecological Risk Assessment of Heavy Metals Accumulated within a Natural Stream of Durgapur Industrial Zone, India, by Using Multivariate Analysis and Pollution Indices. Appl. Water Sci. 2019, 9, 58. [CrossRef]

3. World Health Organization. Action Is Needed on Chemicals of Major Public Health Concern; Public Health and Environment, World Health Organization: Geneva, Switzerland, 2010.

4. Kubier, A.; Wilkin, R.T.; Pichler, T. Cadmium in soils and groundwater: A review. Appl. Geochem. 2019, 108. [CrossRef]

5. Kushwaha, A.; Hans, N.; Kumar, S.; Rani, R. A critical review on speciation, mobilization and toxicity of lead in soil-microbe-plant system and bioremediation strategies. Ecotoxicol. Environ. Saf. 2018, 147, 1035-1045. [CrossRef] [PubMed]

6. Soumya, G.; Moogoui, R.; Gupta, D.K. Arsenic: Source, Occurrence, Cycle, and Detection. In Arsenic Contamination in the Environment: The Issues and Solutions; Gupta, D.K., Chatterjee, S., Eds.; Springer International Publishing: Cham, Switzerland, 2017; pp. 13-35.

7. $\quad$ Pop, C.-E.; Draga, S.; Măciucă, R.; Niță, R.; Crăciun, N.; Wolff, R. Bisphenol A Effects in Aqueous Environment on Lemna minor. Processes 2021, 9, 1512. [CrossRef]

8. Gao, P.; Zhenhong, L.; Huang, S.; Li, K.; Liu, Z.; Xue, G.; Sun, W. Impacts of coexisting antibiotics, antibacterial residues, and heavy metals on the occurrence of erythromycin resistance genes in urban wastewater. Appl. Microbiol. Biotechnol. 2015, 99, 3971-3980. [CrossRef]

9. World Health Organization. Critically Important Antimicrobials for Human Medicine, 6th ed.; World Health Organization: Geneva, Switzerland, 2019.

10. Conley, Z.C.; Bodine, T.J.; Chou, A.; Zechiedrich, L. Wicked: The untold story of ciprofloxacin. PLOS Pathog. 2018, 14, e1006805. [CrossRef]

11. Cuprys, A.; Pulicharla, R.; Brar, S.K.; Drogui, P.; Verma, M.; Surampalli, R.Y. Fluoroquinolones metal complexation and its environmental impacts. Co-ord. Chem. Rev. 2018, 376, 46-61. [CrossRef]

12. Ji, X.; Shen, Q.; Liu, F.; Ma, J.; Xu, G.; Wang, Y.; Wu, M. Antibiotic resistance gene abundances associated with antibiotics and heavy metals in animal manures and agricultural soils adjacent to feedlots in Shanghai; China. J. Hazard. Mater. 2012, 235-236, 178-185. [CrossRef] [PubMed]

13. Nguyen, C.C.; Hugie, C.N.; Kile, M.L.; Navab-Daneshmand, T. Association between heavy metals and antibiotic-resistant human pathogens in environmental reservoirs: A review. Front. Environ. Sci. Eng. 2019, 13, 46. [CrossRef]

14. Afzal, M.Z.; Yue, R.; Sun, X.-F.; Song, C.; Wang, S.-G. Enhanced removal of ciprofloxacin using humic acid modified hydrogel beads. J. Colloid Interface Sci. 2019, 543, 76-83. [CrossRef]

15. Cuprys, A.; Thomson, P.; Ouarda, Y.; Suresh, G.; Rouissi, T.; Brar, S.K.; Drogui, P.; Surampalli, R.Y. Ciprofloxacin removal via sequential electro-oxidation and enzymatic oxidation. J. Hazard. Mater. 2019, 389, 121890. [CrossRef]

16. Wang, S.; Gao, B.; Zimmerman, A.; Li, Y.; Ma, L.; Harris, W.G.; Migliaccio, K. Removal of arsenic by magnetic biochar prepared from pinewood and natural hematite. Bioresour. Technol. 2015, 175, 391-395. [CrossRef]

17. Wan, M.-W.; Kan, C.-C.; Rogel, B.D.; Dalida, M.L.P. Adsorption of copper (II) and lead (II) ions from aqueous solution on chitosan-coated sand. Carbohydr. Polym. 2010, 80, 891-899. [CrossRef]

18. Zeng, Z.-W.; Tan, X.-F.; Liu, Y.-G.; Tian, S.-R.; Zeng, G.-M.; Jiang, L.-H.; Liu, S.-B.; Li, J.; Liu, N.; Yin, Z.-H. Comprehensive Adsorption Studies of Doxycycline and Ciprofloxacin Antibiotics by Biochars Prepared at Different Temperatures. Front. Chem. 2018, 6, 80. [CrossRef] [PubMed]

19. Zhou, Y.; Gao, B.; Zimmerman, A.; Fang, J.; Sun, Y.; Cao, X. Sorption of heavy metals on chitosan-modified biochars and its biological effects. Chem. Eng. J. 2013, 231, 512-518. [CrossRef]

20. Tan, X.; Liu, Y.; Zeng, G.; Wang, X.; Hu, X.; Gu, Y.; Yang, Z. Application of biochar for the removal of pollutants from aqueous solutions. Chemosphere 2015, 125, 70-85. [CrossRef]

21. Palansooriya, K.N.; Kim, S.; Igalavithana, A.D.; Hashimoto, Y.; Choi, Y.-E.; Mukhopadhyay, R.; Sarkar, B.; Ok, Y.S. Fe(III) loaded chitosan-biochar composite fibers for the removal of phosphate from water. J. Hazard. Mater. 2021, 415, 125464. [CrossRef] [PubMed]

22. Bandara, S.; Du, H.; Carson, L.; Bradford, D.; Kommalapati, R. Agricultural and Biomedical Applications of Chitosan-Based Nanomaterials. Nanomaterials 2020, 10, 1903. [CrossRef]

23. Bhatnagar, A.; Sillanpää, M. Applications of chitin- and chitosan-derivatives for the detoxification of water and wastewater-A short review. Adv. Colloid Interface Sci. 2009, 152, 26-38. [CrossRef]

24. Afzal, M.Z.; Sun, X.-F.; Liu, J.; Song, C.; Wang, S.-G.; Javed, A. Enhancement of ciprofloxacin sorption on chitosan/biochar hydrogel beads. Sci. Total. Environ. 2018, 639, 560-569. [CrossRef]

25. Lonappan, L.; Liu, Y.; Rouissi, T.; Pourcel, F.; Brar, S.K.; Verma, M.; Surampalli, R.Y. Covalent immobilization of laccase on citric acid functionalized micro-biochars derived from different feedstock and removal of diclofenac. Chem. Eng. J. 2018, 351, 985-994. [CrossRef]

26. Lonappan, L.; Rouissi, T.; Brar, S.K.; Verma, M.; Surampalli, R.Y. An Insight into the Adsorption of Diclofenac on Different Biochars: Mechanisms, Surface Chemistry, and Thermodynamics. Bioresour. Technol. 2018, 249, 386-394. [CrossRef] [PubMed] 
27. Cuprys, A.; Pulicharla, R.; Lecka, J.; Brar, S.K.; Drogui, P.; Surampalli, R. Ciprofloxacin-metal complexes -stability and toxicity tests in the presence of humic substances. Chemosphere 2018, 202, 549-559. [CrossRef] [PubMed]

28. Samsuri, W.; Sadegh-Zadeh, F.; Seh-Bardan, B.J. Adsorption of As(III) and As(V) by Fe coated biochars and biochars produced from empty fruit bunch and rice husk. J. Environ. Chem. Eng. 2013, 1, 981-988. [CrossRef]

29. Long, H.; Zheng, Y.-J.; Peng, Y.-L.; Jin, G.-Z.; Deng, W.-H.; Zhang, S.-C. Comparison of arsenic(V) removal with different lead-containing substances and process optimization in aqueous chloride solution. Hydrometallurgy 2018, 183, 199-206. [CrossRef]

30. Tran, H.N.; You, S.-J.; Hosseini-Bandegharaei, A.; Chao, H.-P. Mistakes and inconsistencies regarding adsorption of contaminants from aqueous solutions: A critical review. Water Res. 2017, 120, 88-116. [CrossRef]

31. Redlich, O.; Peterson, D.L. A Useful Adsorption Isotherm. J. Phys. Chem 1959, 63, 1024. [CrossRef]

32. Ahmad, Z.; Gao, B.; Mosa, A.; Yu, H.; Yin, X.; Bashir, A.; Ghoveisi, H.; Wang, S. Removal of Cu(II), Cd(II) and Pb(II) ions from aqueous solutions by biochars derived from potassium-rich biomass. J. Clean. Prod. 2018, 180, 437-449. [CrossRef]

33. Jiang, B.; Lin, Y.; Mbog, J.C. Biochar derived from swine manure digestate and applied on the removals of heavy metals and antibiotics. Bioresour. Technol. 2018, 270, 603-611. [CrossRef]

34. Liu, X.; Liu, M.; Zhang, L. Co-adsorption and sequential adsorption of the co-existence four heavy metal ions and three fluoroquinolones on the functionalized ferromagnetic 3D NiFe2O4 porous hollow microsphere. J. Colloid Interface Sci. 2017, 511, 135-144. [CrossRef]

35. Liu, S.; Huang, B.; Chai, L.; Liu, Y.; Zeng, G.; Wang, X.; Zeng, W.; Shang, M.; Deng, J.; Zhou, Z. Enhancement of As(v) adsorption from aqueous solution by a magnetic chitosan/biochar composite. RSC Adv. 2017, 7, 10891-10900. [CrossRef]

36. Niazi, N.K.; Bibi, I.; Shahid, M.; Ok, Y.S.; Burton, E.; Wang, H.; Shaheen, S.; Rinklebe, J.; Lüttge, A. Arsenic removal by perilla leaf biochar in aqueous solutions and groundwater: An integrated spectroscopic and microscopic examination. Environ. Pollut. 2018, 232, 31-41. [CrossRef] [PubMed]

37. Jiang, W.; Lv, J.; Luo, L.; Yang, K.; Lin, Y.; Hu, F.; Zhang, J.; Zhang, S. Arsenate and cadmium co-adsorption and co-precipitation on goethite. J. Hazard. Mater. 2013, 262, 55-63. [CrossRef]

38. Deng, R.; Huang, D.; Wan, J.; Xue, W.; Lei, L.; Wen, X.; Liu, X.; Chen, S.; Yang, Y.; Li, Z.; et al. Chloro-Phosphate Impregnated Biochar Prepared by Co-Precipitation for the Lead, Cadmium and Copper Synergic Scavenging from Aqueous Solution. Bioresour. Technol. 2019, 293, 122102. [CrossRef] [PubMed]

39. Shi, T.; Jia, S.; Chen, Y.; Wen, Y.; Du, C.; Guo, H.; Wang, Z. Adsorption of Pb(Ii), Cr(Iii), Cu(Ii), Cd(Ii) and Ni(Ii) onto a Vanadium Mine Tailing from Aqueous Solution. J. Hazard. Mater. 2009, 169, 838-846. [CrossRef]

40. Chen, H.; Ma, L.Q.; Gao, B.; Gu, C. Influence of $\mathrm{Cu}$ and Ca cations on ciprofloxacin transport in saturated porous media. J. Hazard. Mater. 2013, 262, 805-811. [CrossRef]

41. Tan, Y.; Guo, Y.; Gu, X.; Gu, C. Effects of metal cations and fulvic acid on the adsorption of ciprofloxacin onto goethite. Environ. Sci. Pollut. Res. 2014, 22, 609-617. [CrossRef] 